\title{
Current Perspectives and Mechanisms of Relationship between Intestinal Microbiota Dysfunction and Dementia: A Review
}

\author{
Menizibeya O. Welcome \\ Department of Physiology, Faculty of Basic Medical Sciences, College of Health Sciences, \\ Nile University of Nigeria, Abuja, Nigeria
}

\author{
Keywords \\ Dementia · Intestinal microbiota $\cdot$ Dysbiome repertoire $\cdot$ Gut-brain axis · Microbiota-brain \\ axis
}

\begin{abstract}
Background: Accumulating data suggest a crucial role of the intestinal microbiota in the development and progression of neurodegenerative diseases. More recently, emerging reports have revealed an association between intestinal microbiota dysfunctions and dementia, a debilitating multifactorial disorder, characterized by progressive deterioration of cognition and behavior that interferes with the social and professional life of the sufferer. However, the mechanisms of this association are not fully understood. Summary: In this review, I discuss recent data that suggest mechanisms of cross-talk between intestinal microbiota dysfunction and the brain that underlie the development of dementia. Potential therapeutic options for dementia are also discussed. The pleiotropic signaling of the metabolic products of the intestinal microbiota together with their specific roles in the maintenance of both the intestinal and blood-brain barriers as well as regulation of local, distant, and circulating immunocytes, and enteric, visceral, and central neural functions are integral to a healthy gut and brain. Key Messages: Research investigating the effect of intestinal microbiota dysfunctions on brain health should focus on multiple interrelated systems involving local and central neuroendocrine, immunocyte, and neural signaling of microbial products and transmitters and neurohumoral cells that not only maintain intestinal, but also blood brain-barrier integrity. The change in intestinal microbiome/dysbiome repertoire is crucial to the development of dementia.




\section{Introduction}

The intestinal or gut microbiota can be defined as the overall species of beneficial microbes that inhabit the gastrointestinal tract. The estimated number of these microbes is $\sim 10^{14}$ comprising $\sim 1,000$ species, mainly anaerobic bacteria and archaea, with a fewer number of protozoa, fungi, and other microbes, inhabiting every region of the gut. The gut microbiota represents over $90 \%$ of the total microbes that colonize the human body $[1,2]$.

The intestinal microbes of any region of the gut can substantially influence the health state and development or progression of diseases [3-5]. These microbes regulate homeostasis and metabolism, in part, through their beneficial activities on intestinal and distant histohematological barrier and permeability, immune system functions, gut motility, absorption of nutrients, and synthesis of microbial-derived beneficial bioactive molecules [6, 7]. Though the gut microbiota has a huge beneficial role, it can become potentially harmful, especially under unfavorable conditions of the intestinal microenvironment, possibly resulting from unhealthy diet and nutrition, antibiotic administration, or pathogenic invasion [8-10]. The harmful effects of the intestinal microbiota are due to its abnormal behavior, characterized by the presence of pathogenic microbes or a substantial reduction in the proportion of the intestinal beneficial microbes $[1,8]$.

Emerging data have implicated abnormal intestinal microbiota in the development of dementia [11, 12]. Interestingly, accumulating evidence indicates a key role of the intestinal microbiota in host metabolic regulation, inflammation, synthesis of a couple of molecules that mediate neurohumoral responses, and age-related changes associated with the intestinal microbiota, gut, and functionally related organs $[13,14]$.

Dementia is a devastating complex, multifactorial clinical syndrome, characterized by progressive deterioration of memory, attention, thinking, comprehension, language, and behavior, severe enough to interfere with occupational or social life, which leads to disability, and subsequently death of the individual [15-20]. The growing prevalence of dementia poses a serious public health concern worldwide [15, 16, 21, 22]. In 2003 worldwide prevalence of dementia was 27.7 million [15]. In 2013 the worldwide prevalence of dementia reached 44.4 million [23]. Two years later, precisely in 2015, the number of individuals suffering from dementia reached 46.8 million, indicating an increment of about 1 million per year in new cases. Recent statistics has revealed that the number of demented persons is expected to increase at an alarming rate, reaching 75.6 million by 2030 [23].

Dementia is associated with high financial burden to the caregiver, family, and healthcare system $[17,18,24,25]$. Consequently, the increasing prevalence of dementia in the world will lead to enormous financial burden [23, 24]. In 2003 the worldwide costs for dementia was estimated at USD 156 billion [15]. In 2009 alone, the total worldwide cost of dementia increased to USD 422 billion [26]. It increased to USD 817.9 billion in 2010 [27]. By the end of 2018 it is expected to hit USD 1 trillion [27]. These data indicate an urgent need to step up measures that will identify at-risk individuals, and the necessity for increasing global coalescence for novel translational research on the multiple mechanisms of development of dementia that may lead to the potential discovery of newer frontiers in dementia treatment and identification of specific windows of interactions between certain disorders and the brain that underlie the development of dementia.

The constantly growing prevalence and burden of the disease indicate the necessity to investigate the complex mechanisms that underlie the development of dementia and search for newer avenues that could provide potential therapeutic options for the disease. In this paper, I review recent data that suggest mechanisms of cross-talk between intestinal micro- 
biota dysfunctions and the brain that underlie the development of dementia. Contemporary issues about the intestinal microbiota-brain axis are also discussed. The paper also discusses potential therapeutic options for dementia prevention and development.

\section{Current Perspectives on the Etiopathogenesis of Dementia}

Brain Disorders and Infectious Diseases that Predispose to the Development of Dementia

Dementia is usually caused by neurodegenerative disorders such as multiple sclerosis, Alzheimer's disease, and Parkinson's disease [7,28-31]. Though Alzheimer's disease accounts for approximately $60-75 \%$ of all cases of dementia worldwide $[7,16,32]$, the condition can also occur in up to $80 \%$ of Parkinson's disease patients [28] and about $40-65 \%$ of patients with multiple sclerosis $[33,34]$. Dementia can result from cerebrovascular disease such as stroke (ischemic or hemorrhagic), certain infections such as Creutzfeldt-Jakob disease, herpes simplex virus type 1, human immunodeficiency virus, syphilis, borrelia, toxoplasmosis, cryptococcosis, cysticercosis, cytomegalovirus, Helicobacter pylori, Chlamydophila pneumoniae, Borrelia burgdorferi, Huntington's chorea, corticobasal syndrome, progressive supranuclear palsy, Niemann-Pick disease type $\mathrm{C}$, normal pressure hydrocephalus, and prion diseases. Alcohol misuse can also cause dementia [7, 21, 28, 30, 35-38]. These brain disorders lead to inflammation or dysfunctions in neural or glial metabolism that eventually result in loss of connections, and eventually death of brain cells that characterize dementia [7, 21]. However, depending on the physiological reserve of the organism and induction of the compensatory mechanisms, cognitive impairment leading to dementia may be static, progressive, or reversible $[30,39,40]$.

\section{Advanced Glycation End Products due to Senescence as a Possible Cause of Dementia}

Several reports have revealed that nonenzymatic glycosylation of proteins due to senescence form advanced glycation end products that are resistant to proteolytic processing and can induce protein cross-linking, resulting in induction of oxidative stress and free radical formation, and possibly formation and accumulation of $\beta$-amyloid, and inflammation as in the case of Alzheimer's progressive cognitive impairment or dementia [41-45]. The receptors for the harmful metabolites and proinflammatory molecules due to oxidative stress in neurons and glia (microglia and astrocytes) are believed to mediate the pathological processes observed in dementia [46]. These receptors include the following: NLRP1 (nucleotide-binding oligomerization domain-like receptor containing pyrin domain 1), NLRP2-5, NLRP9, and NLRP10; TREM2 (triggering receptor expressed on myeloid cells 2), SRA (scavenger receptor type A); scavenger receptor B-1 (SRB-1); MARCO (macrophage receptor with collagenous structure); RAGE (receptor for advanced-glycosylation end products) and the receptors of the complement system such as Fc receptors; FPR2 (formyl peptide receptor 2); CD11 (cluster of differentiation 11), CD21, CD33, CD35, CD36, CD45, CD68, CD88, and complement receptor 3a and 5a (CD88); TLR2 (toll-like receptor type 2), TLR3, TLR4, TLR6, and TLR7; CMKLR1 (chemokine-like receptor 1); CXCR5 (C-X-C motif chemokine receptor 5) and CXCR16; EP2 (prostaglandin E2 receptor subtype 2); FPR1 and FPRL1 (formyl peptide receptor type 1 and formyl peptide receptor like 1); and leukocyte immunoglobulin-like receptor B2 (LilrB2) among others [47-56]. All these receptors are known as pattern recognition receptors (PRRs) [57-59]. PRRs sense and recognize certain motifs on pathogens (pathogen-associated molecular patterns, PAMPs) or molecules released due to cellular damage (damage-associated molecular patterns, DAMPs) [60]. Examples of PAMPs include peptidoglycan, lipopolysaccharides, triacyl lipoproteins, zymosan, teichoic acid, lipoteichoic acid, lipoarabinomannan, arabinogalactan, lipopeptides, flagellin, and foreign nuclear mate- 
rials such as bacterial DNA and viral RNA, which can trigger the production of proinflammatory cytokines that may trigger the onset of certain peripheral and central diseases characterized by inflammatory reactions [60]. Examples of DAMPs include certain extracellular matrix components released during cell damage (e.g., laminin, fibronectin, elastin, and collagen-derived peptides, matrix metalloproteinase- 3 and -13 , versican, and biglycan) and cytoplasmic proteins such as heat shock proteins (e.g., Hsp60), RNA and mitochondrial DNA, nuclear DNA, IL-1, high-mobility group box 1 protein, histones, adenosine triphosphate, and antimicrobial peptides - which are altogether known as "alarmins" [60-68]. The recognition of PAMPs or DAMPs by PRRs (e.g., TLRs, CD14) activates signaling pathways such as nuclear factor kappa of B cell (NF- $\mathrm{KB}$ ) and inducible nitric oxide synthase (iNOS), leading to the synthesis of proinflammatory cytokines and interferons (IFN- $\gamma$ ), and tumor necrosis factor alpha (TNF- $\alpha$ ), as well as the activation of a range of oxidative stress-related molecules including MAPK (mitogen-activated protein kinase), PI3K (phosphatidylinositol 3-kinase), PKC (protein kinase C), AP-1 (activator protein 1), p38, and numerous autophagy pathways $[60,62,63,69]$. PAMPs signal downstream via the JAK-STAT (Janus kinase/signal transducers and activators of transcription) pathway to initiate the synthesis of interleukins and TNF- $\alpha$ [70]. This pathway of proinflammatory cytokine synthesis is termed the MyD88dependent pathway because signaling through this pathway occurs via activation of the cytoplasmic adaptor protein myeloid differentiation primary response protein 88 (MyD88). However, there is also an MyD88-independent pathway that controls IFN- $\beta$ synthesis and activity [60]. This "recognition signaling" occurs at the local (gut epithelium) and central level (brain). In reality, the host cell uses multiple pathways to recognize pathogenic microbes. For instance, the pattern recognition molecules MBL (mannose-binding lectin) and ficolins functioning as opsonins can form a linkage with MBL-associated serine protease-2 (MASP-2), resulting to the formation of MBL-MASP-2 complex, which can recognize and bind to certain carbohydrate motifs on the microbial cell wall to initiate a series of reactions that culminate in the production of proinflammatory cytokines. The signaling of these cytokines can result in altered balance or composition of the intestinal microbes, and as a consequence, increased intestinal permeability $[60,71-73]$. The proinflammatory cytokines can be transported to different tissues including the brain, initiating a neuroinflammatory process in the blood-brain barrier that decreases its permeability $[60,74,75]$. These processes and the signaling cascades mediated by the activation of the amyloid peptide receptors also interact with a range of neurotransmitter systems, which add to the deterioration of cognitive functions [76-78].

\section{A Possible Role of the Siderocalin-Brain-Type Organic Cation Transporter 1-Megalin Complex, Mediating Neuroinflammation, in the Development of Dementia}

The recent discovery of the ubiquitous lipocalin-2 (also known as siderocalin) and its purported role in the brain has sparked considerable interest in the behavior and signaling pathway mediated by this secreted glycoprotein. Though information about the peptide is scanty, functional lipocalin-2 forms a complex with brain-type organic cation transporter 1 and megalin (also known as low-density lipoprotein-related protein 2, LRP2) and contributes to the transport of small hydrophobic molecules. Interestingly the microglial, astroglial, epithelial, and neuronal type of this complex has been shown to be involved in neuroinflammation [79-81]. Furthermore, LRP2, a receptor for $\beta$-amyloid protein, has been implicated in late-onset Alzheimer's disease. In addition to LRP2, LRP1 can form complexes with apolipoprotein $\mathrm{E}$ to mediate clearance of $\beta$-amyloid protein across the blood-brain barrier. Pharmacological agents that will affect the activities of LRP1 are currently considered potential therapeutic options for the treatment of Alzheimer's disease [82-84]. 


\section{Inorganic Deposits in the Brain as a Possible Cause of Dementia}

Inorganic deposits in the brain can initiate free radical processes that result in lipid peroxidation, protein oxidation, formation of reactive oxygen species, and subsequently accumulation of calcium ion that results to excitatory toxicity [85]. These processes underlie oxidative stress, which activates microglia, at least in part, by stimulating PRRs (e.g., TLRs), resulting in phagocytosis of the toxic molecules. The result of these processes may lead to neurodegeneration [86-88]. Previous studies showed that murine microglial cells exposed in vitro to aluminosilicate particles stimulated the generation of free radical reactive oxygen metabolites such as hydrogen peroxide, superoxide, and hydroxyl free radicals, leading to tissue injury $[89,90]$. Indeed, human studies of Alzheimer's disease have confirmed deposits of inorganic metals in amyloid deposits in specific brain regions [91-93].

Toxic metals activate signaling pathways related to redox transcription factors such as NF- $\kappa B, A P-1$, MTF-1 (metal-responsive transcription factor 1), p53 (53-kilodalton tumor protein), ethylene responsive transcription factor 1 (ERF1), ERF2, Ref-1 (redox factor 1), extracellular-signal-regulated kinases (ERK1/2), and c-Jun NH 2-terminal kinase (JNK) [9499]. Indeed. some deposits that characterize senile dementia have been observed to contain inorganic aluminosilicate particles [90]. Interestingly, amyloid deposits that characterize Alzheimer's dementia or progressive cognitive impairment were shown to result in lipid peroxidation and protein phosphorylation, altering glucose metabolism and the mTOR signaling pathway, leading to neuronal death [100].

\section{Toxigenic Metabolites and Dementia}

Toxic products of cellular metabolism can also cause neuroinflammation or brain tissue or vascular injury that subsequently leads to demyelination and neurodegeneration $[87,88$, $90,101,102]$. Indeed, dementia due to vascular dysfunction accounts for about $15-30 \%$ of all dementia cases [30]. A ${ }^{1}$ H-MRS study by Herminghaus et al. [103] (2003) found that concentration of certain metabolites, in particular $N$-acetyl aspartate, was decreased, while total creatine and myo-inositol were significantly increased in the brain of Alzheimer's disease patients. However, comorbid factors may be responsible for the association between metabolic dysfunctions and cognitive impairment [104]. This association has been reviewed elsewhere [105].

\section{Alteration in the Composition of Beneficial Intestinal Microbiota as a Possible Cause of} Dementia

A couple of studies have shown alterations in the intestinal microbiota in dementia [7, 9-12]. A substantial decrease in intestinal microbes, especially Lactobacillus and Bifidobacterium, as well as changes in Coprobacillus, Dorea, Enterococcaceae, Staphylococcus, Faecalibacterium, Coprococcus, and Roseburia, are believed to be responsible for cognitive impairment and cerebral hypometabolism in neurodegeneration that characterize dementia [106]. The essential role of the intestinal microbiota in regulating both local and distant tissues such as the blood-brain barrier is mediated via multiple mechanisms, which are discussed below [6, $7,13,14]$.

\section{Functional Communication Pathways between the Intestinal Microbiota and the Brain}

The connection between the gut and the brain has been suggested since antiquity when the Greek philosophers and scientists suggested a possible relationship between gut disorders and epilepsy [1, 2]. In fact, Hippocrates around 400 B.C. even quoted that "death sits in the 


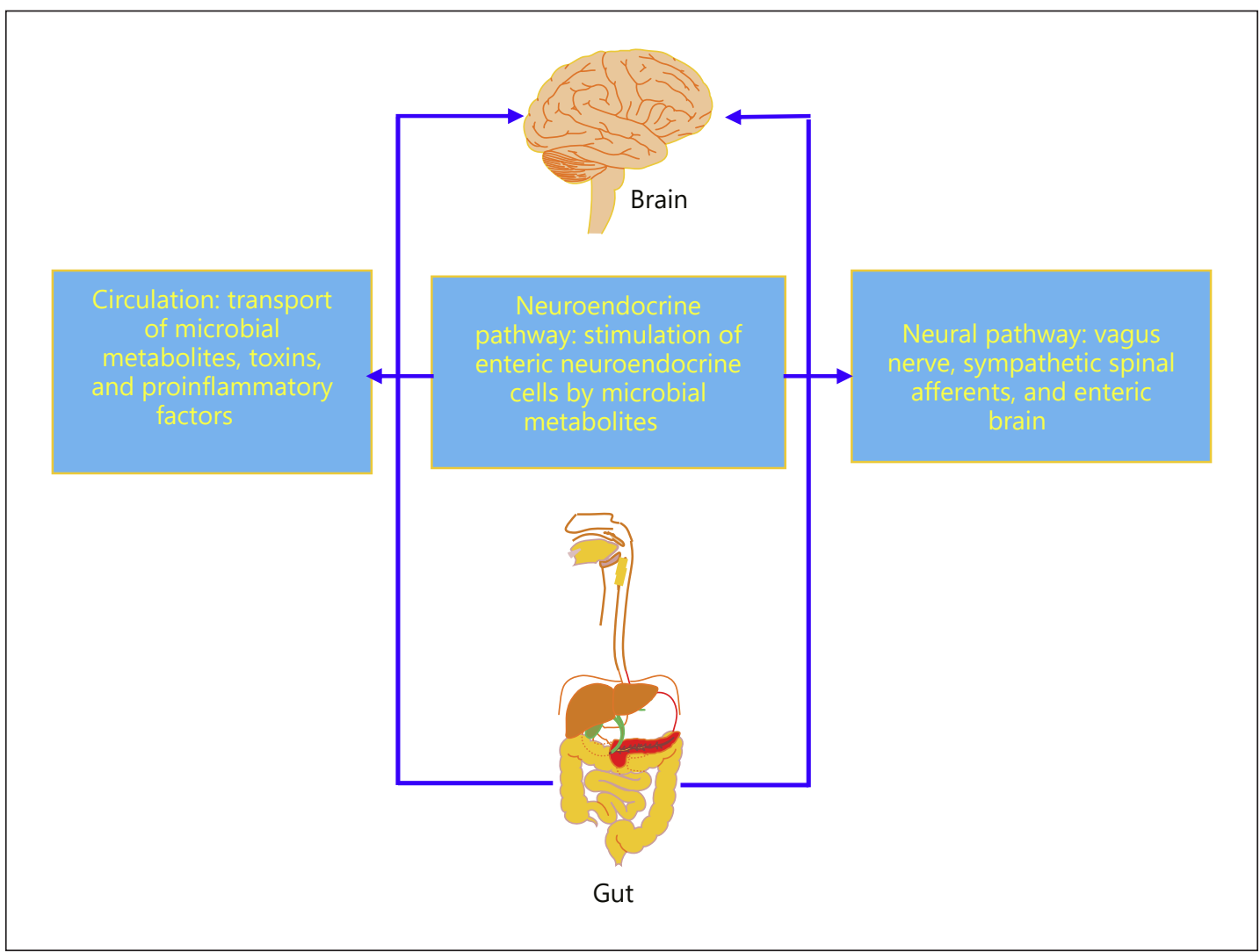

Fig. 1. Pathways of gut microbiota-brain cross-talk.

bowels," possibly referring to the disorders associated with bowel malfunctioning [107]. It should be noted, however, that the gut microbiota-dementia connection represents only a portion of the gut-brain axis. The functional pathways through which the intestinal microbiota communicate with the brain, also known as intestinal microbiota-brain cross-talk, is a bidirectional functional communication network between the microbes and the brain that comprises neuroendocrine, neural, and neuroimmune signaling pathways (Fig. 1). The endocrine pathway is mediated by the interaction between the intestinal microbiota and neuroendocrine cells of the gut. The neural pathway of intestinal microbiota-brain cross-talk occurs through the interaction of the intestinal microbiota with the central nervous system (including the hypothalamic-pituitary-adrenal axis, HPA axis), the autonomic nervous system (via the vagus nerve and the sympathetic nerve fibers), and the enteric nervous system. The immune pathway that mediates the cross-talk occurs through the interaction between the intestinal microbiota and immune molecules [108-110].

The metabolites of the intestinal microbiota such as short-chain fatty acids, GABA ( $\gamma$-amino butyric acid), serotonin, norepinephrine, histamine, etc. regulate a range of physiological processes in the gut and distant organs, including the brain, via their interaction with neural, neuroendocrine, and immune signaling pathways [108, 110-114].

\section{Intestinal Microbiota-Neural Signaling}

In recent papers, I noted that the gut alone synthesizes over sixty types of transmitter molecules that not only influence gut functions, but also nervous system activity $[115,116]$. 
Thus, dysfunctions in the gut homeostasis due to dysfunction in intestinal microbiota can result in disorder in the synthesis of the gut neurotransmitters, neuropeptides, hormones, and immunomodulators, which can affect the gut-brain axis [60]. Some of the gut-derived hormones can affect the functions and composition of the intestinal microbiota. Surprisingly, not only the gut cells synthesize these neurotransmitters, neuropeptides, hormones, and immunomodulators, but also the intestinal microbiota. Furthermore, the gut microbiota can trigger the synthesis of these molecules from epithelial neuroendocrine cells of the gut. So, the cholinogenic gut microbe, Lactobacillus sp., produces acetylcholine that affects vagal, neuroendocrine, and neuroimmune signaling. Bacillus sp. is a dopaminergic microbe [7, 115, 116]. The intestinal microbiota regulates the HPA axis by the release of cortisol, which may affect microglia activation and cytokine release, homing of distant and local immunocytes to the site of cerebral aggression. The intestinal microbiota can affect long-term potentiation (LTP) via its interaction and regulation of GABA, N-methyl-D-aspartate (NMDA) receptor, postsynaptic density marker 95 (PSD-95), and brain-derived neurotrophic factor (BDNF) $[117,118]$. LTP is an important phenomenon in higher mental functions, memory formation, and cognitive processes in which activity-dependent processes are persistently enhanced at neuronal synapses $[119,120]$. Dysfunction in LTP induction has been implicated in a range of cognitive impairments that accompany ageing including Alzheimer's disease and dementia $[120,121]$.

\section{Intestinal Microbiota-Endocrine Signaling}

A couple of endocrine factors released by the intestinal microbiota or secreted by the endocrine cells of the gut under the action of the intestinal microbiota can be transported via the circulatory system to the brain where they trigger a range of signaling pathways responsible for higher mental functioning $[6,115]$. On the other hand, substances released by the brain can also affect the activities of the gut and intestinal microbiota [6]. Thus, the endocrine pathway represents a crucial bidirectional link between the gut microbiota and brain structures that allows the transfer of humoral factors, which mediate a range of brain activities including cognition $[122,123]$. Gut-derived hormones regulate energy homeostasis and exert a substantial influence on the gut's little brain and central nervous system, thereby modulating cognitive functions $[1,60,75]$.

Intestinal microbiota dysfunctions result in alteration in microbe- and gut-synthesized hormones including neurotrophic factors and their receptor systems [124, 125], which may predispose to the development of neuronal and glial cell death. Growth hormones protect neurons from toxicity and excessive excitatory signaling [126], in part by stabilizing $\mathrm{Ca}^{2+}$ signaling, stabilizing the expression and NMDA and GABA receptor-mediated signaling [115, $116,126]$. In addition, adequate humoral signaling exerts protective effects on the mitochondria. This way, growth factors prevent neurodegenerative processes that result in dementia [75]. Furthermore, the gut-synthesized hormones leptin, ghrelin, glucagon-like peptide 1 , and glucose-dependent insulinotropic polypeptide confer neuroprotective effects against neurotoxicity induced by harmful pathogenic microbial toxins (toxigenic metabolites) [126-128]. Consequently, application of analogs of these hormones can be helpful in the treatment of cases of dementia.

Intestinal Microbiota Signaling Is Coupled to Second Messenger Generation: Cooperativity or Confluence of Neural and Endocrine Signaling Pathways?

$\mathrm{Ca}^{2+}$ is a second messenger that links several signaling pathways in the cell. This cellular ion is required to maintain ongoing physiological processes. However, prolonged or excessive increase can become detrimental to the cell $[115,116,129,130]$. Importantly, destabilization of $\mathrm{Ca}^{2+}$ signaling has been implicated in neurodegeneration $[126,131,132]$. Dysfunctional 
$\mathrm{Ca}^{2+}$ signaling due to alteration in intestinal microbiota can occur both in the gut and brain. Disorder in intestinal microbiota can result in accumulation of $\mathrm{Ca}^{2+}$ ions, which can lead to cellular toxicity. Although the mechanisms are not fully understood, it may involve multiple disorders involving functional protein complexes (e.g., claudins, occludins, and zonula adherens) which increase paracellular shunt activity in the gut epithelium. This may lead to excessive excitation of the extracellular G-protein-coupled $\mathrm{Ca}^{2+}$ sensing receptor (CaSR) located on different cells of the gut including neuroendocrine and vagal nerve endings [115, $116,130,133-135]$.

Activation of this receptor can occur not only by extracellular $\mathrm{Ca}^{2+}$, but also other molecules including $\mathrm{Mg}^{2+}$, amino acids, polyamines, and drugs (CaSR agonists or calcimimetics and calcilytics or CaSR antagonists) $[136,137]$. But there may be a bidirectional relationship between the CaSR and the intestinal microbiota. A relatively recent report revealed that deficiency of this receptor resulted to intestinal microbiota dysfunction, in addition to reduced intestinal barrier and disordered immune response. This suggests that CaSR may serve as a therapeutic target in dysfunctions of the intestinal microbiota [138].

The vagus nerve endings that mediate signal transfer in the microbiota-gut-brain axis express the CaSR. Consequently, dysfunctions of CaSR signaling in the vagus nerve have been associated with disorder in neurotransmission associated with this nerve and its integrating center with excitatory and inhibitory outputs to multiple brain regions $[115,116,130,133$, 135]. Moreover, accumulation of $\mathrm{Ca}^{2+}$ in the cytosol of both neurons and glial cells can activate proteases and lipases, which degrade plasma membrane proteins and lipid molecules to generate free radicals that further cause destruction of cellular components. Accumulation of cytosolic $\mathrm{Ca}^{2+}$ can also activate $\mathrm{Ca}^{2+}$-dependent proteases, resulting in hyperphosphorylation of microtubule proteins, triggering changes in the cytoskeleton, similar to those observed in dementia $[115,116,130-132]$.

\section{Dementia-Dysbiome Repertoire}

Sudo et al. [139] were the first to report a link between the gut microbiota and the brain. They reported stress response mediated by the HPA axis and decreased BDNF levels in the hippocampus of germ-free mice. Since then, there has been increased interest in studying the functional connectivity between the brain and intestinal microbiota in normal and pathological cells $[6,140]$. Recent studies have shown that intestinal microbiota dysfunctions may underlie the development of progressive cognitive impairment or dementia [10-12]. A recent analysis identified a strong association between dementia and dysbiosis of the intestinal microbiota or dysbiome - the total population of harmful microbes that predisposes to the development of dementia [12]. The number of Clostridium difficile in patients with dementia was substantially increased compared to controls [12].

The intestinal microbe Cyanobacteria, occurring during gut dys-homeostasis, can synthesize neurotoxins such as saxitoxin, $\alpha$-anatoxin, and $\beta$ - $N$-methylamino-L-alanine, which may contribute to the development of dementia [7]. Some gut microbes including Citrobacter, Escherichia coli, Klebsiella, Mycobacteria, Pseudomonas, Streptococcus, Streptomyces, Staphylococcus, Salmonella, and Bacillus species among others are capable of synthesizing amyloid peptides (e.g., curli amyloid fibers, $A \beta_{42}$, having CsgA as the major subunits, but also containing $\mathrm{CsgB}$ ) that are transported and deposited in the brain and may potentially cause cognitive impairment or dementia [7, 72, 141-143]. By a mechanism of molecular mimicry, these bacterial amyloids can cause neuroinflammation and subsequently neurodegeneration by interfering with inflammatory pathways mediated by TLR2 and NF- $\kappa B$ signaling [144]. The bacterial amyloids also exert local effects on the gut by destroying the protective defenses of 


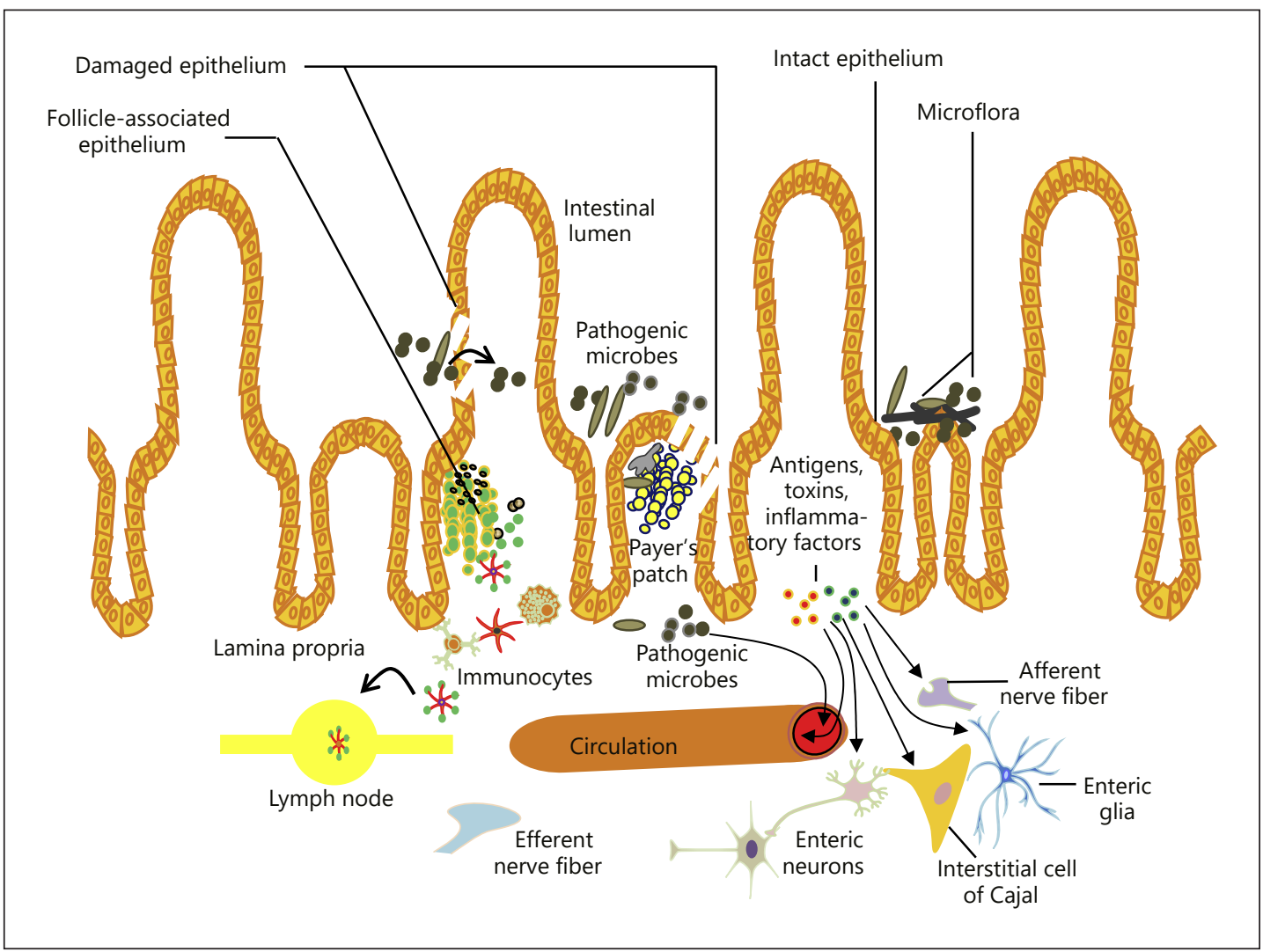

Fig. 2. The gut mucosa showing intact epithelium and defective epithelium resulting from pathogenic microbial activity, which causes disorder in the sentinel system of the gut (mucous membrane, follicle-associated epithelium, Peyer patches, lymph nodes, resident immunocytes). The defect enhances translocation of pathogenic microbes and toxigenic metabolites, as well as proinflammatory factors, to different regions of the gut where they trigger local inflammatory response, activating immunocytes. The pathogenic microbes and toxigenic metabolites, as well as proinflammatory and inflammatory factors, released from the site of defect and during local inflammatory responses can be transported via circulation to the brain $[1,112]$. Furthermore, the toxic metabolites and other substances released can stimulate the enteric brain comprising the enteric glia, the enteric neurons, and the interstitial cells of Cajal, and also regulate the activity and synthesis machinery of neuroendocrine cells and afferent fibers of the vagus and spinal nerves. The lymphatic vessels are also implicated in the inflammatory responses [1].

the host, at least in part, through enhancement of surface adhesion of pathogenic microbes and biofilm development [7, 141-143].

A decrease in the number of Bifidobacteria, including B. fragilis, and Eubacterium rectale correlates with cerebrospinal fluid biomarkers of Alzheimer's disease [145, 146]. The results of these studies raise important questions as to whether or not some microbes are responsible for the development of dementia. Causative agents of neurodegeneration are yet to be identified [147]. There is currently no effective treatment for dementia as conventional strategies identify patients very late and the treatment usually addresses the symptoms and not the underlying causes $[7,101]$. As a result, the prevalence of dementia continues to increase worldwide [148]. In all neurodegenerative diseases associated with dementia there is a reported difference in the composition of gut microbiota compared to that in healthy individuals [7, 146,147]. Moreover, age-related changes in the composition of the gut microbiota are also associated with dementia [11, 149]. 
The gut microbiota is responsible for modulating several gut hormones and peptides, including cholecystokinin, corticotropin-releasing factor, neuropeptide Y, peptide YY, pancreatic polypeptide, serotonin, glucagon-like peptide, and ghrelin, which through the vagal and spinal afferents, neuroendocrine and immunocyte signaling can exert a considerable impact on brain functions $[140,150]$. Furthermore, the intestinal microbiota has been shown to control the metabolic pathways of synthesis of certain neurotransmitters. The intestinal microbiota regulates the kynurenine pathway involved in tryptophan metabolism, which is required for the synthesis of serotonin [108].

\section{Dysfunctional Intestinal Microbiota Is Associated with Disordered Intestinal and Blood- Brain Barriers: Decrease in Beneficial Intestinal Bacteria and Increase in Potentially Harmful Ones Enhances the Development of Dementia}

The increase in permeability of the intestinal and blood-brain barriers is critical to the transport of toxigenic metabolites to the brain (Fig. 2). Toxic metabolites such as trimethylamine $\mathrm{N}$-oxide, D-amino acids, hippurate, phenylacetylglutamine, polyamines including putrescine, cadaverine, agmatine, and tyramine, acrolein, $p$-cresol sulfate, indoxyl sulfate, indole- 3 acetic, phenol- and sulfur-containing compounds, as well as ammonia produced by the intestinal microbes can destroy the junctional complexes of the intestinal epithelial lining, thereby increasing the leakiness of the gut [151-165] (immune responses triggered by these microbial metabolites are integral to leaky gut [163-165]). This increases impairment in selective transport and paracellular shunt of substances between the gut and circulatory system, allowing for unregulated movement of biomolecules including toxins into the surrounding tissues and circulatory system from the luminal side of the gut (Fig. 2) [166].

The toxigenic metabolites can disrupt the endothelium of the blood-brain barrier by altering the expression of sealing claudins, which are supposed to preserve the permeability of the blood-brain barrier (Fig. 2,3) [156, 167-170]. In addition, adherens proteins, membrane transporters, basal lamina, and extracellular matrix are affected [151]. Disorder in the expression of sealing claudins and other membrane components of the blood-brain barrier increases the development of neurodegenerative disorders due to unregulated translocation of toxic metabolites, leading to loss of neurons, astrocytes, microglia, endothelial cells, and pericytes (Fig. 3) [151, 171, 172]. Indeed, defects in blood-brain barrier components as well as glial cells have been observed in many neurodegenerative diseases including Alzheimer's disease [147, 173-186].

\section{Decrease in Beneficial Intestinal Microbiota Metabolites is a Fundamental Factor in the}

Development of Dementia: Implication for New Therapeutic Options

The gut microbiota generates multiple biologically relevant molecules including vitamin Kand the $B$ group $\left(B_{1}, B_{2}, B_{3}, B_{5}, B_{6}, B_{8}, B_{9}\right.$, and $\left.B_{12}\right)$, certain amino acids, polyphenols (including flavonoids), and short-chain fatty acids such as propionate, acetate, butyrate, valerate, isovalerate, and iso-butyrate, which modulate both peripheral and central processes to tissue or cellular injury [187-189]. The gut microbiota metabolites are either used locally by the epithelial cells of the gut or transported to different tissues and cells of the body via the circulatory system to exert an array of effects. Of particular interest are the short-chain fatty acids, which are metabolic products of the action of the intestinal microbiota on certain carbohydrates that are nondigestible by the host cells [190-193]. The short-chain fatty acids exert their effects on the host cells through the activation of G-protein-coupled receptors (GPR41, GPR43, and GPR109), modulating the activities of certain epithelial ion channels and neurohumoral responses of the gut and distant tissues and organs [194-197]. The short-chain fatty acids play a crucial neuromodulatory role in gut neuroendocrine cells and enterocytes, func- 
tioning as chemotaxins, antioxidants, antitumorigens, antimicrobial and anti-inflammatory agents in the gut, and distant tissues including the brain $[75,197]$. Dementia and other neurodegenerative disorders including some gut diseases are characterized by a significant decrease in the beneficial metabolites produced by the intestinal microbiota. Consequently, measures that will lead to elevation of these metabolites in the gut and bloodstream can enhance gut and brain functions in several diseases. The short-chain fatty acid propionate was shown to stimulate intestinal gluconeogenesis, decrease stress, and enhance memory. This short-chain fatty acid stimulates the G-protein-coupled receptor, free fatty acid receptor type 2, located on the epithelial cells of the gut and brain endothelium [171, 198-200]. Activation of the free fatty acid receptor on colonic enteroendocrine cells by the short-chain fatty acid can stimulate the recruitment of synaptic or membrane vesicle-loaded glucagon-like

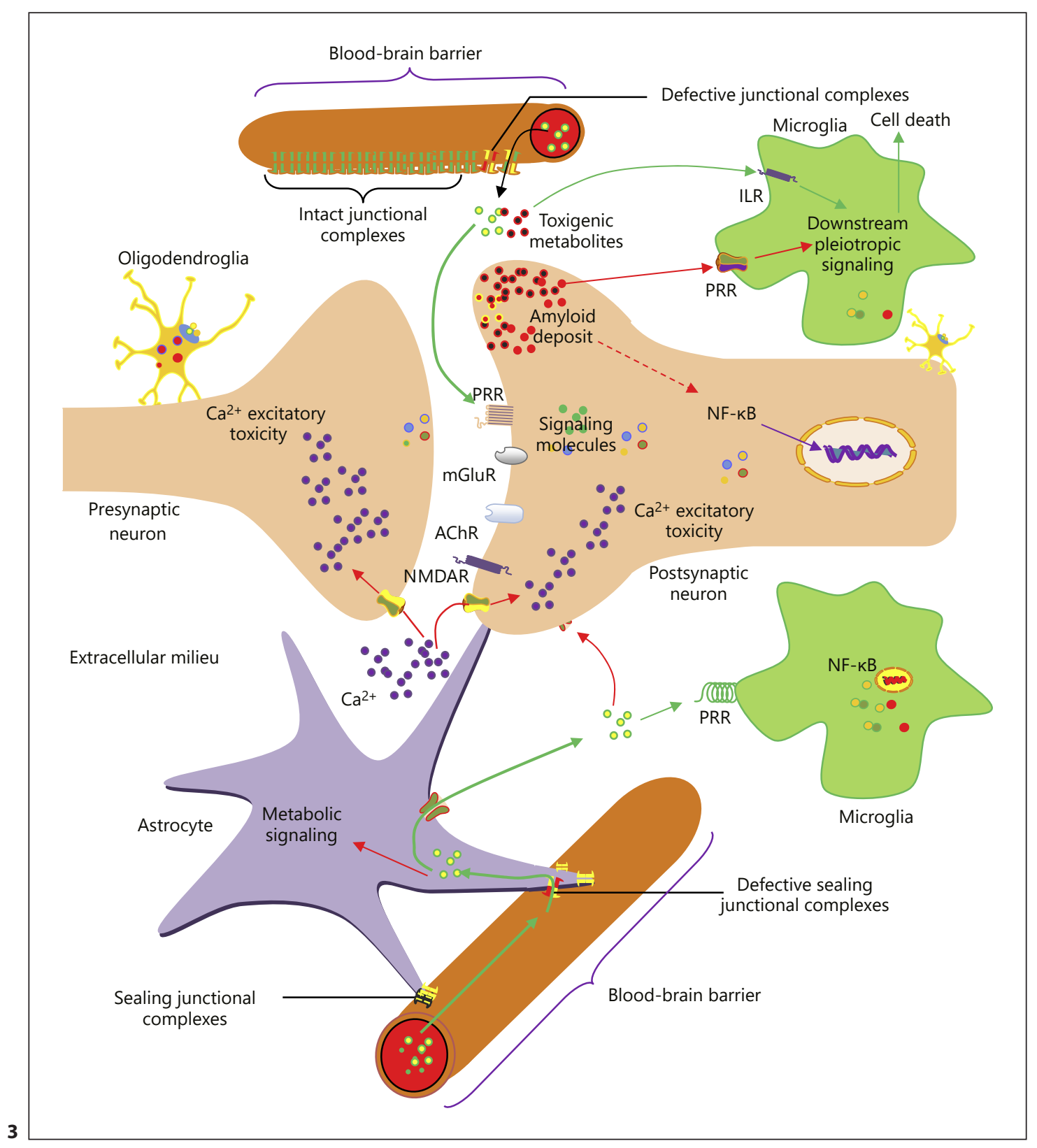


peptide 1, peptide YY, and other neuropeptides towards the plasma membrane for exocytosis [201]. Furthermore, short-chain fatty acids such as propionate can halt infections by controlling CD14 signaling, suppressing the expression of low-density lipoprotein receptorrelated protein 1 , and reducing oxidative stress via activation of the nuclear factor (erythroidderived 2)-like 2, a guardian of human lifespan that protects against ageing and diseases [171, 202, 203].

Both preclinical and clinical trials have shown the beneficial effects of the administration of agents that enhance the growth of intestinal microbiota [204-208]. Furthermore, emerging results of clinical trials have revealed immense benefits of the application of intestinal microbes in the treatment of disorders of the gut and brain $[209,210]$.

\section{Clinical Trials on the Effects of Intestinal Microbiota and Related Products or Their Activators on Gut Health and Cognitive Functions}

Transplantation or ingestion of specific intestinal microbiota and products that promote the growth of the beneficial microbes are increasingly gaining attention around the globe. For instance, preclinical trials of prebiotics, probiotics, and synbiotics have

Fig. 3. Translocation and generation of toxic metabolites to the neuroglial circuitry mediating cognitive functions. The toxins cause defects in the blood-brain barrier leading to increased translocation of more toxic metabolites and proinflammatory factors to the brain. These factors (e.g., proinflammatory cytokines and chemokines) mediate intracellular signaling that lead to protein and lipid breakdown, mitochondrial dysfunction, and disordered transport processes that culminate in neuroinflammation and neurodegeneration characterized for dementia and other brain diseases [120,121]. For instance, dysbiosis has been associated with increased circulating neurotoxic interleukin mediators, which in turn predispose to the development of neurodegenerative diseases $[6,96]$. Furthermore, ageing is associated with increased circulating neurotoxic mediators such as TNF- $\alpha$, IL-6, and C-reactive protein, which can directly cause low-grade inflammation, that predispose the individual to the development of dementia and other diseases including diabetes [6]. The microbe-derived amyloids on the membrane of neurons, glia, and epithelial cells can stimulate pattern recognition receptors (PRRs) such as TLRs, causing local and possibly systemic inflammation, at least in part through their interaction with Peyer patches and other immune components of the gut [53]. Increased production of toxic metabolites by the activities of disordered gut microbiota has been implicated in metabolic disorders and local and systemic inflammatory responses [105-107]. As part of the toxic metabolites transported to the brain, amyloids can initiate a series of intracellular signaling via activation of PPRs such as RAGE, resulting in the activation of microglia [40] and phagocytosis of the amyloids [122,123]. The binding of the metabolites or amyloids also initiate downstream signaling mediated via NF- $\mathrm{KB}$ pathways with resultant activation of the expression of proinflammatory cytokines, resulting in neuroinflammation, excitotoxicity, and oxidative stress $[124,125]$. Pathological signaling of proinflammatory cytokines such as IL-1 $\beta$, IL-6, and TNF- $\alpha$ via the JAK-STAT (Janus kinase/signal transducers and activators of transcription) pathway in the central nervous system can disorganize microtubules via yet unknown mechanisms that lead to dysfunctions of microglia, the main immune sentinels of the central nervous system [126-129]. These microglia progressively lose the ability to clear cellular debris including amyloid proteins, which further stimulate signaling cascades that culminate in cell death $[126,127]$. In the case of dementia due to Alzheimer's disease, the accumulating amyloid deposits provoke an inflammatory response that disorganizes the several protective mechanisms that favor neurodegeneration [38]. In addition, signaling pathways that initiate gene transcription such as p38 and other protein kinases are activated [127]. Furthermore, dysfunctions of amyloid peptide-degrading enzymes such as insulysin, neprilysin, and matrix metallopeptidase 9 have been reported in an animal model of dementia [128]. All these processes lead to neurodegeneration which favors the development of dementia or worsens the progression of the disease $[124,125]$. It should be noted, however, that PRRs are regulated by molecules such as nucleotide-binding oligomerization domain (NOD)-like receptor (NLRs) and Toll-interacting protein (TOLLIP) among others [1, 3]. Toxigenic metabolites that favor the development of dementia and other neurodegenerative diseases may cause substantial defects in these regulatory peptides, thereby resulting to neuroimmune defects that underlie the development of the disease $[1,3]$. 
shown promise for decreasing dysbiosis, and attenuating neuroinflammation and cognitive disorder. The beneficial effects of prebiotics, probiotics, and synbiotics are due to their action on the enteric nervous system, neuroendocrine system, and vagus, as well as spinal nerve fibers of the gut [204, 205, 207]. Certain microbial agents used as supplements to benefit the host are termed probiotics. Probiotics such as Lactobacillus paracasei, $L$. acidophilus, L. casei, L. fermentum, L. helveticus, L. rhamnosus, Bifidobacterium bifidum, $B$. longum, $B$. breve, and $B$. infantis enhance the central nervous system expression of BDNF, NMDA receptor subunits involved in LTP, synaptophysin, and other neuropeptides and synaptic components involved in synaptic and neural plasticity to improve memory and behavior, and decrease anxiety, depression, and a range of neurological and psychiatric disorders [97, 211-216]. Probiotics also affect the expression of neurotrophic factors in the enteric brain $[213,217]$.

The usefulness of probiotics is due to their pleiotropic signaling capabilities. They interfere with a range of cellular pathways implicated in the maintenance of homeostasis. For instance, oral probioticotherapy enhances the serum level of tryptophan, which is a precursor of serotonin [118]. Furthermore, an increase in the number of beneficial intestinal microbiota is due to the crucial influence of probiotics. In all, the effects of these beneficial microbes culminate in improved endocrine, immune, and neural signaling, and carbohydrate, protein, and lipid metabolism, which have a summative effect in the attenuation of neuroinflammation, thereby preventing neurodegeneration [218]. In a randomized, doubleblind, controlled trial, it was revealed that a daily probiotic milk supplementation for 12 weeks in Alzheimer's type dementia patients resulted in a significant improvement in cognitive functions [205]. Evaluation of inflammatory markers showed their substantial reduction, while the patients' metabolic status showed improvement [205]. In another randomized controlled trial, Santocchi et al. [219] (2016) reported that probiotic supplementation in autistic patients resulted in a significant improvement in gut dysfunctions, cognition, and language. In their randomized, double-blind, placebo-controlled clinical trial on patients with major depressive disorder, Akkasheh et al. [204] (2016) reported that probiotic supplementation with L. acidophilus, L. casei, and B. bifidum, at a dose of $2 \times 10^{9}$ $\mathrm{CFU} / \mathrm{g}$ each for 8 weeks, resulted in improvement in symptoms of depression and metabolic state, as well as a decrease in markers of oxidative stress and inflammation. These clinical trials have evidently shown promise for the application of the beneficial intestinal microbes for dementia therapeutics.

Prebiotics are nondigestible food components ingested by the host, but under the fermentative influence of the intestinal microbiota, they confer a range of health benefits to the host. Prebiotics are carbohydrate substances, mainly oligosaccharides. Substances with prebiotic effects include resistant starch, inulin, oligofructose, lactulose, galactooligosaccharides, xyloolidosaccharides, fructo-oligosaccharides, transgalactooligosaccharides, polydextrose, acacia gum, banana, psyllium, wheat dextrin, whole grain corn, and whole grain wheat [210, 213, 220-222]. Like the probiotics, prebiotics improve gut health, memory, and cognition, and decrease anxiety, depression, and stress [213, 222]. Prebiotics are associated with a decrease in microglial activation, and improvement in brain mitochondrial function and hippocampal plasticity. The result is attenuation of neuroinflammation and reduction in neurodegeneration [212]. Synbiotics are a combination of probiotics and prebiotics. Synbiotics also exert a profound beneficial influence on gut health and the central nervous system [212].

A new clinical trial revealed that a high initial dose followed by a lower daily maintenance dose of microbiota transfer therapy for 8 weeks results in improvement in intestinal microbiota composition and significantly reduces symptoms of gut and neurological disorders [210]. Analysis of a colony of intestinal microbiota over the therapy period revealed a 
substantial increase in the beneficial microbes Bifidobacterium, Prevotella, Bacteroides fragiles, and Desulfovibrio [210]. Successful application of fecal microbiota transfer therapy is reported elsewhere [209]. An ongoing clinical trial "Microbiome and Dementia" on the effects of fecal microbiota transfer therapy on demented patients is currently underway (2017-2018) (ClinicalTrials.gov, NCT03167983).

\section{Factors Influencing Intestinal Microbiota-Brain Cross-Talk}

Several factors, mainly ageing, genetic, and environmental factors, influence the intestinal microbiota composition and functions as well as the brain to modulate processes that predispose to the development and progression of dementia [223-228]. Age, environment, and genes are important factors that determine or shape the development and progression of dementia and related neurodegenerative diseases [229]. Substantial changes in the composition of the intestinal microbiota and the gut functions occur during ageing [226-228], which may underlie age-related cognitive impairment or dementia. Certain changes in the genome or epigenome of the gut and brain cells may occur due to environmental insults. These changes can have enormous effects on the gut-brain, intestinal gut microbiota-gut and intestinal gut microbiota-brain axes [38].

\section{Conclusion}

The intestinal microbiota is a population of health-promoting microbes that controls a couple of cellular signaling pathways and metabolic processes via multiple mechanisms involving immune, neural, and neuroendocrine pathways. These pathways constitute a critical nexus between the intestinal microbiota and the brain. However, the intestinal microbes are affected by several factors, which may result in a reduction in the population of health-promoting microbes. The intestinal microbiota plays a critical role in the etiopathogenesis of neurodevelopmental, psychiatric, and neurodegenerative disorders. The association between disorder of the intestinal microbiota and dementia is due to the peculiar role of the metabolic products of the beneficial microbes together with their specific roles in the maintenance of both the intestinal and blood-brain barriers as well as regulation of local, circulating, and distant immunocytes, and enteric, visceral, and central neural functions. It is therefore imperative for studies investigating the impact of gut microbiota on gut and brain health to focus on multiple interrelated systems and organs involving local and central neuroendocrine, immunocyte, and neural signaling of microbial products and transmitter molecules of the intestinal residents and neurohumoral cells that not only maintain the gut, but also the integrity of the blood-brain barrier.

\section{Disclosure Statement}

There is no conflict of interest regarding the publication of this paper. 


\section{References}

1 Welcome MO, Mastorakis NE, Pereverzev VA. Neuropsychological functions of the gut microbiota. In: Chiappelli F, editor. Advances in Psychobiology. New York, USA: Nova Science Publishers; 2018. pp. 267-79.

2 Welcome MO. History of development of gastrointestinal physiology: from antiquity to modern period and the birth of modern digestive physiology. In. Welcome MO, editor. Gastrointestinal physiology: development, principles and mechanisms of regulation. Cham: Springer; 2018. pp 1-51. DOI: https://doi.org/10.1007/9783-319-91056-7.

3 Lerner A, Matthias T. Gut - the Trojan horse in remote organs' autoimmunity. J Clin Cell Immunol. 2016; 7:401.

4 Lerner A, Matthias T. Extra intestinal manifestations of CD: common pathways in the gut-remote organs' axes. Int J Celiac Dis. 2017;5(1):24-7.

5 Lerner A, Aminov R, Matthias T. Dysbiosis may trigger autoimmune diseases via inappropriate post-translational modification of host proteins. Front Microbiol. 2016 Feb; 7:84.

6 Welcome MO. Functional relationship between the gut and other tissues/organs of the body. In: Welcome MO, editor. Gastrointestinal physiology: development, principles and mechanisms of regulation. Cham: Springer; 2018. pp 1009-1028. DOI: https://doi.org/10.1007/978-3-319-91056-7.

7 Alkasir R, Li J, Li X, Jin M, Zhu B. Human gut microbiota: the links with dementia development. Protein Cell. 2017 Feb;8(2):90-102.

8 Lerner A, Neidhöfer S, Matthias T. The gut microbiome feelings of the brain: a perspective for non-microbiologists. Microorganisms. 2017 Oct;5(4):66.

9 Jiang C, Li G, Huang P, Liu Z, Zhao B. The gut microbiota and Alzheimer's disease. J Alzheimers Dis. 2017;58(1): $1-15$.

10 Hu X, Wang T, Jin F. Alzheimer's disease and gut microbiota. Sci China Life Sci. 2016 Oct; 59(10):1006-23.

11 Buford TW. (Dis)Trust your gut: the gut microbiome in age-related inflammation, health, and disease. Microbiome. 2017 Jul;5(1):80.

12 Araos R, Andreatos N, Ugalde J, Mitchell S, Mylonakis E, D’Agata EM. Fecal microbiome among nursing home residents with advanced dementia and Clostridium difficile. Dig Dis Sci. 2018 Jun;63(6):1525-31.

13 O’Toole PW, Jeffery IB. Gut microbiota and aging. Science. 2015 Dec;350(6265):1214-5.

14 Fransen F, van Beek AA, Borghuis T, Aidy SE, Hugenholtz F, van der Gaast-de Jongh C, et al. Aged Gut Microbiota Contributes to Systemical Inflammaging after Transfer to Germ-Free Mice. Front Immunol. 2017 Nov;8: 1385.

15 Wimo A, Jonsson L, Winblad B. An estimate of the worldwide prevalence and direct costs of dementia in 2003. Dement Geriatr Cogn Disord. 2006;21(3):175-81.

16 Hung YN, Kadziola Z, Brnabic AJ, Yeh JF, Fuh JL, Hwang JP, et al. The epidemiology and burden of Alzheimer's disease in Taiwan utilizing data from the National Health Insurance Research Database. Clinicoecon Outcomes Res. 2016 Aug;8:387-95.

17 Fiest KM, Jetté N, Roberts JI, Maxwell CJ, Smith EE, Black SE, et al. The prevalence and incidence of dementia: a systematic review and meta-analysis. Can J Neurol Sci. 2016 Apr;43(S1 Suppl 1):S3-50.

18 de Jager CA, Msemburi W, Pepper K, Combrinck MI. Dementia prevalence in a rural region of South Africa: a cross-sectional community study. J Alzheimers Dis. 2017;60(3):1087-96.

19 Chertkow H, Feldman HH, Jacova C, Massoud F. Definitions of dementia and predementia states in Alzheimer's disease and vascular cognitive impairment: consensus from the Canadian conference on diagnosis of dementia. Alzheimers Res Ther. 2013 Jul;5 Suppl 1:S2.

20 James BD, Schneider JA. Increasing incidence of dementia in the oldest old: evidence and implications. Alzheimers Res Ther. 2010 May;2(3):9.

21 Rizzi L, Rosset I, Roriz-Cruz M. Global epidemiology of dementia: Alzheimer's and vascular types. BioMed Res Int. 2014;2014:908915.

22 Fratiglioni L, De Ronchi D, Agüero-Torres H. Worldwide prevalence and incidence of dementia. Drugs Aging. 1999 Nov; 15(5):365-75.

23 Xu J, Wang J, Wimo A, Fratiglioni L, Qiu C. The economic burden of dementia in China, 1990-2030: implications for health policy. Bull World Health Organ. 2017 Jan;95(1):18-26.

24 Wimo A, Winblad B, Jönsson L. The worldwide societal costs of dementia: estimates for 2009. Alzheimers Dement. 2010 Mar;6(2):98-103.

25 Neugroschl J, Wang S. Alzheimer's disease: diagnosis and treatment across the spectrum of disease severity. Mt Sinai J Med. 2011 Jul-Aug;78(4):596-612.

26 Wimo A, Jönsson L, Bond J, Prince M, Winblad B; Alzheimer Disease International. The worldwide economic impact of dementia 2010. Alzheimers Dement. 2013 Jan;9(1):1-11.e3.

27 Wimo A, Guerchet M, Ali GC, Wu YT, Prina AM, Winblad B, et al. The worldwide costs of dementia 2015 and comparisons with 2010. Alzheimers Dement. 2017 Jan;13(1):1-7.

28 Robinson L, Tang E, Taylor JP. Dementia: timely diagnosis and early intervention. BMJ. 2015 Jun;350:h3029.

29 Inglese M, Petracca M. Imaging multiple sclerosis and other neurodegenerative diseases. Prion. 2013 Jan-Feb; $7(1): 47-54$.

30 Chaudhuri K, Samarakoon SM, Chandola HM, Kumar R, Ravishankar B. Evaluation of diet and life style in etiopathogenesis of senile dementia: A survey study. Ayu. 2011 Apr;32(2):171-6. 
31 Du X, Wang X, Geng M. Alzheimer's disease hypothesis and related therapies. Transl Neurodegener. 2018 Jan; $7(1): 2$.

32 Dong S, Duan Y, Hu Y, Zhao Z. Advances in the pathogenesis of Alzheimer's disease: a re-evaluation of amyloid cascade hypothesis. Transl Neurodegener. 2012 Sep;1(1):18.

33 Chiaravalloti ND, DeLuca J. Cognitive impairment in multiple sclerosis. Lancet Neurol. 2008 Dec;7(12):113951.

34 Rao SM, Leo GJ, Bernardin L, Unverzagt F. Cognitive dysfunction in multiple sclerosis. I. Frequency, patterns, and prediction. Neurology. 1991 May;41(5):685-91.

35 Knopman DS. Dementia and cerebrovascular disease. Mayo Clin Proc. 2006 Feb;81(2):223-30.

36 Almeida OP, Lautenschlager NT. Dementia associated with infectious diseases. Int Psychogeriatr. 2005;17(S1 Suppl 1):S65-77.

37 Mawanda F, Wallace R. Can infections cause Alzheimer's disease? Epidemiol Rev. 2013;35(1):161-80.

38 Dunn N, Mullee M, Perry VH, Holmes C. Association between dementia and infectious disease: evidence from a case-control study. Alzheimer Dis Assoc Disord. 2005 Apr-Jun;19(2):91-4.

39 Larson EB, Kukull WA, Katzman RL. Cognitive impairment: dementia and Alzheimer's disease. Annu Rev Public Health. 1992;13(1):431-49.

40 Mathews SB, Arnold SE, Epperson CN. Hospitalization and cognitive decline: can the nature of the relationship be deciphered? Am J Geriatr Psychiatry. 2014 May;22(5):465-80.

41 Thome J, Kornhuber J, Münch G, Schinzel R, Taneli Y, Zielke B, et al. [New hypothesis on etiopathogenesis of Alzheimer syndrome. Advanced glycation end products (AGEs)]. Nervenarzt. 1996 Nov;67(11):924-9. German.

42 Takeuchi M, Yamagishi S. Possible involvement of advanced glycation end-products (AGEs) in the pathogenesis of Alzheimer's disease. Curr Pharm Des. 2008;14(10):973-8.

43 Cai Z, Hussain MD, Yan LJ. Microglia, neuroinflammation, and beta-amyloid protein in Alzheimer's disease. Int J Neurosci. 2014 May;124(5):307-21.

44 Lovestone S, Smith U. Advanced glycation end products, dementia, and diabetes. Proc Natl Acad Sci USA. 2014 Apr;111(13):4743-4.

45 Yaffe K, Lindquist K, Schwartz AV, Vitartas C, Vittinghoff E, Satterfield S, et al. Advanced glycation end product level, diabetes, and accelerated cognitive aging. Neurology. 2011 Oct;77(14):1351-6.

46 Srikanth V, Maczurek A, Phan T, Steele M, Westcott B, Juskiw D, et al. Advanced glycation endproducts and their receptor RAGE in Alzheimer's disease. Neurobiol Aging. 2011 May;32(5):763-77.

47 Wang Y, Ulland TK, Ulrich JD, Song W, Tzaferis JA, Hole JT, et al. TREM2-mediated early microglial response limits diffusion and toxicity of amyloid plaques. J Exp Med. 2016 May;213(5):667-75.

48 Doens D, Fernández PL. Microglia receptors and their implications in the response to amyloid $\beta$ for Alzheimer's disease pathogenesis. J Neuroinflammation. 2014 Mar;11(1):48.

49 Yu Y, Ye RD. Microglial A $\beta$ receptors in Alzheimer's disease. Cell Mol Neurobiol. 2015 Jan;35(1):71-83.

50 Okuneva O, Li Z, Körber I, Tegelberg S, Joensuu T, Tian L, et al. Brain inflammation is accompanied by peripheral inflammation in Cstb -/- mice, a model for progressive myoclonus epilepsy. J Neuroinflammation. 2016 Nov; 13(1):298.

51 Rayaprolu S, Mullen B, Baker M, Lynch T, Finger E, Seeley WW, et al. TREM2 in neurodegeneration: evidence for association of the p.R47H variant with frontotemporal dementia and Parkinson's disease. Mol Neurodegener. 2013 Jun;8(1):19.

52 Carneiro LA, Travassos LH. The Interplay between NLRs and Autophagy in Immunity and Inflammation. Front Immunol. 2013 Nov; 4:361.

53 Nagyőszi P, Nyúl-Tóth Á, Fazakas C, Wilhelm I, Kozma M, Molnár J, et al. Regulation of NOD-like receptors and inflammasome activation in cerebral endothelial cells. J Neurochem. 2015 Nov;135(3):551-64.

54 Mandrekar-Colucci S, Landreth GE. Microglia and inflammation in Alzheimer's disease. CNS Neurol Disord Drug Targets. 2010 Apr;9(2):156-67.

55 Doens D, Fernández PL. Microglia receptors and their implications in the response to amyloid $\beta$ for Alzheimer's disease pathogenesis. J Neuroinflammation. 2014 Mar; 11:48.

56 Rubio-Perez JM, Morillas-Ruiz JM. A review: inflammatory process in Alzheimer's disease, role of cytokines. ScientificWorldJournal. 2012;2012:756357.

57 Gordon S. Pattern recognition receptors: doubling up for the innate immune response. Cell. 2002 Dec;111(7): 927-30.

58 Takeuchi O, Akira S. Pattern recognition receptors and inflammation. Cell. 2010 Mar;140(6):805-20.

59 Kalantari P. The emerging role of pattern recognition receptors in the pathogenesis of malaria. Vaccines (Basel). 2018 Feb;6(1):13.

60 Welcome MO. Immunomodulatory functions of the gastrointestinal tract. In: Welcome MO, editor. Gastrointestinal physiology: development, principles and mechanisms of regulation. Cham: Springer; 2018. pp 685-771. DOI: https://doi.org/10.1007/978-3-319-91056-7_10.

61 Skandalis SS, Dobra K, Götte M, Karousou E, Misra S. Impact of extracellular matrix on cellular behavior: a source of molecular targets in disease. Biomed Res Int. 2015;2015:482879.

62 Land WG. The Role of Damage-Associated Molecular Patterns (DAMPs) in Human Diseases: Part II: DAMPs as diagnostics, prognostics and therapeutics in clinical medicine. Sultan Qaboos Univ Med J. 2015 May; 15(2):e157-70. 
63 Kim SH, Turnbull J, Guimond S. Extracellular matrix and cell signalling: the dynamic cooperation of integrin, proteoglycan and growth factor receptor. J Endocrinol. 2011 May;209(2):139-51.

64 Theocharis AD, Skandalis SS, Gialeli C, Karamanos NK. Extracellular matrix structure. Adv Drug Deliv Rev. 2016 Feb; 97:4-27.

65 Tang D, Kang R, Coyne CB, Zeh HJ, Lotze MT. PAMPs and DAMPs: signal 0s that spur autophagy and immunity. Immunol Rev. 2012 Sep;249(1):158-75.

66 Bianchi ME. DAMPs, PAMPs and alarmins: all we need to know about danger. J Leukoc Biol. 2007 Jan;81(1): $1-5$.

67 Tsan MF. Heat shock proteins and high mobility group box 1 protein lack cytokine function. J Leukoc Biol. 2011 Jun;89(6):847-53.

68 Zhang Q, Raoof M, Chen Y, Sumi Y, Sursal T, Junger W, et al. Circulating mitochondrial DAMPs cause inflammatory responses to injury. Nature. 2010 Mar;464(7285):104-7.

69 McCarthy CG, Goulopoulou S, Wenceslau CF, Spitler K, Matsumoto T, Webb RC. Toll-like receptors and damageassociated molecular patterns: novel links between inflammation and hypertension. Am J Physiol Heart Circ Physiol. 2014 Jan;306(2):H184-96.

70 Friedland RP, Chapman MR. The role of microbial amyloid in neurodegeneration. PLoS Pathog. 2017 Dec; 13(12):e1006654.

71 Kilpatrick DC, Chalmers JD. Human L-ficolin (ficolin-2) and its clinical significance. J Biomed Biotechnol. 2012; 2012:138797.

72 Degn SE, Jensen L, Olszowski T, Jensenius JC, Thiel S. Co-complexes of MASP-1 and MASP-2 associated with the soluble pattern-recognition molecules drive lectin pathway activation in a manner inhibitable by MAp44. J Immunol. 2013 Aug;191(3):1334-45.

73 Møller-Kristensen M, Thiel S, Sjöholm A, Matsushita M, Jensenius JC. Cooperation between MASP-1 and MASP-2 in the generation of C3 convertase through the MBL pathway. Int Immunol. 2007 Feb;19(2):141-9.

74 Foster JA, Rinaman L, Cryan JF. Stress \& the gut-brain axis: regulation by the microbiome. Neurobiol Stress. 2017 Mar; 7:124-36.

75 Bonfili L, Cecarini V, Berardi S, Scarpona S, Suchodolski JS, Nasuti C, et al. Microbiota modulation counteracts Alzheimer's disease progression influencing neuronal proteolysis and gut hormones plasma levels. Sci Rep. 2017 May; 7(1):2426.

76 Madsen K, Neumann WJ, Holst K, Marner L, Haahr MT, Lehel S, et al. Cerebral serotonin 4 receptors and amyloid- $\beta$ in early Alzheimer's disease. J Alzheimers Dis. 2011;26(3):457-66.

77 Severino M, Sivasaravanaparan M, Olesen LØ, von Linstow CU, Metaxas A, Bouzinova EV, et al. Established amyloid- $\beta$ pathology is unaffected by chronic treatment with the selective serotonin reuptake inhibitor paroxetine. Alzheimers Dement (N Y). 2018 May;4:215-23.

78 Danysz W, Parsons CG. Alzheimer's disease, $\beta$-amyloid, glutamate, NMDA receptors and memantinesearching for the connections. Br J Pharmacol. 2012 Sep;167(2):324-52.

79 Kjeldsen L, Johnsen AH, Sengeløv H, Borregaard N. Isolation and primary structure of NGAL, a novel protein associated with human neutrophil gelatinase. J Biol Chem. 1993 May;268(14):10425-32.

80 Song J, Kim OY. Perspectives in Lipocalin-2: Emerging Biomarker for Medical Diagnosis and Prognosis for Alzheimer's Disease. Clin Nutr Res. 2018 Jan;7(1):1-10.

81 Chia WJ, Tan FC, Ong WY, Dawe GS. Expression and localisation of brain-type organic cation transporter (BOCT/24p3R/LCN2R) in the normal rat hippocampus and after kainate-induced excitotoxicity. Neurochem Int. 2015 Aug;87:43-59.

82 Shinohara M, Tachibana M, Kanekiyo T, Bu G. Role of LRP1 in the pathogenesis of Alzheimer's disease: evidence from clinical and preclinical studies. J Lipid Res. 2017 Jul;58(7):1267-81.

83 Martiskainen H, Haapasalo A, Kurkinen KM, Pihlajamäki J, Soininen H, Hiltunen M. Targeting ApoE4/ApoE receptor LRP1 in Alzheimer's disease. Expert Opin Ther Targets. 2013 Jul;17(7):781-94.

84 Wang LL, Pan XL, Wang Y, Tang HD, Deng YL, Ren RJ, et al. A single nucleotide polymorphism in LRP2 is associated with susceptibility to Alzheimer's disease in the Chinese population. Clin Chim Acta. 2011 Jan; 412(3-4): 268-70.

85 Varadarajan S, Yatin S, Aksenova M, Butterfield DA. Review: alzheimer's amyloid beta-peptide-associated free radical oxidative stress and neurotoxicity. J Struct Biol. 2000 Jun;130(2-3):184-208.

86 Evans PH, Klinowski J, Yano E. Cephaloconiosis: a free radical perspective on the proposed particulate-induced etiopathogenesis of Alzheimer's dementia and related disorders. Med Hypotheses. 1991 Mar;34(3):209-19.

87 Gambuzza ME, Sofo V, Salmeri FM, Soraci L, Marino S, Bramanti P. Toll-like receptors in Alzheimer's disease: a therapeutic perspective. CNS Neurol Disord Drug Targets. 2014;13(9):1542-58.

88 Yin Z, Raj D, Saiepour N, Van Dam D, Brouwer N, Holtman IR, et al. Immune hyperreactivity of A $\beta$ plaque-associated microglia in Alzheimer's disease. Neurobiol Aging. 2017 Jul;55:115-22.

89 Evans PH, Yano E, Klinowski J, Peterhans E. Oxidative damage in Alzheimer's dementia, and the potential etiopathogenic role of aluminosilicates, microglia and micronutrient interactions. EXS. 1992;62:178-89.

90 Evans PH. Free radicals in brain metabolism and pathology. Br Med Bull. 1993 Jul;49(3):577-87.

91 Maynard CJ, Bush AI, Masters CL, Cappai R, Li QX. Metals and amyloid- $\beta$ in Alzheimer's disease. Int J Exp Pathol. 2005 Jun;86(3):147-59.

92 Mathys ZK, White AR. Copper and Alzheimer's disease. Adv Neurobiol. 2017;18:199-216. 
93 Szabo ST, Harry GJ, Hayden KM, Szabo DT, Birnbaum L. Comparison of metal levels between postmortem brain and ventricular fluid in Alzheimer's disease and nondemented elderly controls. Toxicol Sci. 2016 Apr;150(2): 292-300.

94 Valko M, Morris H, Cronin MT. Metals, toxicity and oxidative stress. Curr Med Chem. 2005;12(10):1161-208.

95 Koedrith P, Seo YR. Advances in carcinogenic metal toxicity and potential molecular markers. Int J Mol Sci. 2011;12(12):9576-95.

96 Nzengue Y, Candéias SM, Sauvaigo S, Douki T, Favier A, Rachidi W, et al. The toxicity redox mechanisms of cadmium alone or together with copper and zinc homeostasis alteration: its redox biomarkers. J Trace Elem Med Biol. 2011 Jul;25(3):171-80.

97 Hasan MK, Liu C, Wang F, Ahammed GJ, Zhou J, Xu MX, et al. Glutathione-mediated regulation of nitric oxide, S-nitrosothiol and redox homeostasis confers cadmium tolerance by inducing transcription factors and stress response genes in tomato. Chemosphere. 2016 Oct;161:536-45.

98 Huff MO, Todd SL, Smith AL, Elpers JT, Smith AP, Murphy RD, et al. Arsenite and cadmium activate MAPK/ERK via membrane estrogen receptors and G-protein coupled estrogen receptor signaling in human lung adenocarcinoma cells. Toxicol Sci. 2016 Jul;152(1):62-71.

99 Adams TK, Saydam N, Steiner F, Schaffner W, Freedman JH. Activation of gene expression by metal-responsive signal transduction pathways. Environ Health Perspect. 2002 Oct;110(5 Suppl 5):813-7.

100 Butterfield DA, Boyd-Kimball D. oxidative stress, amyloid- $\beta$ peptide, and altered key molecular pathways in the pathogenesis and progression of Alzheimer's disease. J Alzheimers Dis. 2018;62(3):1345-67.

101 Iemolo F, Duro G, Rizzo C, Castiglia L, Hachinski V, Caruso C. Pathophysiology of vascular dementia. Immun Ageing. 2009 Nov;6(1):13.

102 Tong XK, Hamel E. Regional cholinergic denervation of cortical microvessels and nitric oxide synthasecontaining neurons in Alzheimer's disease. Neuroscience. 1999;92(1):163-75.

103 Herminghaus S, Frölich L, Gorriz C, Pilatus U, Dierks T, Wittsack HJ, et al. Brain metabolism in Alzheimer disease and vascular dementia assessed by in vivo proton magnetic resonance spectroscopy. Psychiatry Res. 2003 Jul;123(3):183-90.

104 Panza F, Frisardi V, Seripa D, Imbimbo BP, Sancarlo D, D’Onofrio G, et al. Metabolic syndrome, mild cognitive impairment, and dementia. Curr Alzheimer Res. 2011 Aug;8(5):492-509.

105 Frisardi V, Solfrizzi V, Seripa D, Capurso C, Santamato A, Sancarlo D, et al. Metabolic-cognitive syndrome: a cross-talk between metabolic syndrome and Alzheimer's disease. Ageing Res Rev. 2010 Oct;9(4):399-417.

106 Sanguinetti E, Collado MC, Marrachelli VG, Monleon D, Selma-Royo M, Pardo-Tendero MM, et al. Microbiomemetabolome signatures in mice genetically prone to develop dementia, fed a normal or fatty diet. Sci Rep. 2018 Mar;8(1):4907.

107 Sbahi H, Di Palma JA. Faecal microbiota transplantation: applications and limitations in treating gastrointestinal disorders. BMJ Open Gastroenterol. 2016 May;3(1):e000087.

108 O'Mahony SM, Clarke G, Borre YE, Dinan TG, Cryan JF. Serotonin, tryptophan metabolism and the brain-gutmicrobiome axis. Behav Brain Res. 2015 Jan;277:32-48.

109 Thakur AK, Shakya A, Husain GM, Emerald M, Kumar V. Gut-Microbiota and Mental Health: Current and Future Perspectives. J Pharmacol Clin Toxicol. 2014;2(1):1016.

110 Dinan TG, Cryan JF. Gut instincts: microbiota as a key regulator of brain development, ageing and neurodegeneration. J Physiol. 2017 Jan;595(2):489-503.

111 Cristiano C, Lama A, Lembo F, Mollica MP, Calignano A, Mattace Raso G. Interplay Between Peripheral and Central Inflammation in Autism Spectrum Disorders: Possible Nutritional and Therapeutic Strategies. Front Physiol. 2018 Mar; 9:184.

112 Lin L, Zhang J. Role of intestinal microbiota and metabolites on gut homeostasis and human diseases. BMC Immunol. 2017 Jan;18(1):2.

113 Rowland I, Gibson G, Heinken A, Scott K, Swann J, Thiele I, et al. Gut microbiota functions: metabolism of nutrients and other food components. Eur J Nutr. 2018 Feb;57(1):1-24.

114 Rooks MG, Garrett WS. Gut microbiota, metabolites and host immunity. Nat Rev Immunol. 2016 May;16(6): 341-52.

115 Welcome MO. Gastrointestinal hormones. In: Welcome MO, editor. Gastrointestinal physiology: development, principles and mechanisms of regulation. Cham: Springer; 2018. pp 455-526. DOI:https://doi. org/10.1007/978-3-319-91056-7_8.

116 Welcome MO. Neural secretions and regulation of gut functions. In: Welcome MO, editor. Gastrointestinal physiology: development, principles and mechanisms of regulation. Cham. Springer, 2018. pp 527-684. DOI: https://doi.org/10.1007/978-3-319-91056-7.

117 Yoshiike Y, Kimura T, Yamashita S, Furudate H, Mizoroki T, Murayama M, et al. GABA(A) receptor-mediated acceleration of aging-associated memory decline in APP/PS1 mice and its pharmacological treatment by picrotoxin. PLoS One. 2008 Aug;3(8):e3029.

118 Wang H, Lee IS, Braun C, Enck P. Effect of probiotics on central nervous system functions in animals and humans: a systematic review. J Neurogastroenterol Motil. 2016 Oct;22(4):589-605.

119 Skaper SD, Facci L, Zusso M, Giusti P. Synaptic plasticity, dementia and Alzheimer disease. CNS Neurol Disord Drug Targets. 2017;16(3):220-33.

120 Boric K, Muñoz P, Gallagher M, Kirkwood A. Potential adaptive function for altered long-term potentiation mechanisms in aging hippocampus. J Neurosci. 2008 Aug;28(32):8034-9. 
121 Lynch MA. Age-related impairment in long-term potentiation in hippocampus: a role for the cytokine, interleukin-1 beta? Prog Neurobiol. 1998 Dec;56(5):571-89.

122 Clarke G, Stilling RM, Kennedy PJ, Stanton C, Cryan JF, Dinan TG. Minireview: Gut microbiota: the neglected endocrine organ. Mol Endocrinol. 2014 Aug;28(8):1221-38.

123 Farzi A, Fröhlich EE, Holzer P: Gut Microbiota and the Neuroendocrine System. Neurotherapeutics 2018 Jan; 15(1):5-22.

124 Ghaisas S, Maher J, Kanthasamy A. Gut microbiome in health and disease: linking the microbiome-gut-brain axis and environmental factors in the pathogenesis of systemic and neurodegenerative diseases. Pharmacol Ther. 2016 Feb;158:52-62.

125 Carding S, Verbeke K, Vipond DT, Corfe BM, Owen LJ. Dysbiosis of the gut microbiota in disease. Microb Ecol Health Dis. 2015 Feb;26:26191.

126 Mattson MP, Barger SW, Cheng B, Lieberburg I, Smith-Swintosky VL, Rydel RE. beta-Amyloid precursor protein metabolites and loss of neuronal Ca2+ homeostasis in Alzheimer's disease. Trends Neurosci. 1993 Oct;16(10): 409-14.

127 Bayliss JA, Lemus M, Santos VV, Deo M, Elsworth JD, Andrews ZB. Acylated but not des-acyl ghrelin is neuroprotective in an MPTP mouse model of Parkinson's disease. J Neurochem. 2016 May;137(3):460-71.

128 Shen XL, Song N, Du XX, Li Y, Xie JX, Jiang H. Nesfatin-1 protects dopaminergic neurons against MPP+/MPTPinduced neurotoxicity through the C-Raf-ERK1/2-dependent anti-apoptotic pathway. Sci Rep. 2017 Jan; 7(1): 40961.

129 Welcome MO. Molecular mechanisms of gastrointestinal signaling. In: Welcome MO, editor. Gastrointestinal physiology: development, principles and mechanisms of regulation. Cham: Springer; 2018. pp 227-315. DOI:https://doi.org/10.1007/978-3-319-91056-7_5.

130 Dufner MM, Kirchhoff P, Remy C, Hafner P, Müller MK, Cheng SX, et al. The calcium-sensing receptor acts as a modulator of gastric acid secretion in freshly isolated human gastric glands. Am J Physiol Gastrointest Liver Physiol. 2005 Dec;289(6):G1084-90.

131 Smith-Swintosky VL, Mattson MP. Glutamate, beta-amyloid precursor proteins, and calcium mediated neurofibrillary degeneration. J Neural Transm Suppl. 1994;44:29-45.

132 Cheng SX, Lightfoot YL, Yang T, Zadeh M, Tang L, Sahay B, et al. Epithelial CaSR deficiency alters intestinal integrity and promotes proinflammatory immune responses. FEBS Lett. 2014 Nov;588(22):4158-66.

133 Riccardi D, Brown EM. Physiology and pathophysiology of the calcium-sensing receptor in the kidney. Am Physiol Renal Physiol. 2010 Mar;298(3):F485-99.

134 Tang L, Cheng CY, Sun X, Pedicone AJ, Mohamadzadeh M, Cheng SX. The Extracellular Calcium-Sensing Receptor in the Intestine: Evidence for Regulation of Colonic Absorption, Secretion, Motility, and Immunity. Front Physiol. 2016 Jun; 7:245.

135 Owen JL, Cheng SX, Ge Y, Sahay B, Mohamadzadeh M. The role of the calcium-sensing receptor in gastrointestinal inflammation. Semin Cell Dev Biol. 2016 Jan;49:44-51.

136 Zhang C, Miller CL, Gorkhali R, Zou J, Huang K, Brown EM, et al. Molecular Basis of the Extracellular Ligands Mediated Signaling by the Calcium Sensing Receptor. Front Physiol. 2016 Sep;7:441.

137 Vahe C, Benomar K, Espiard S, Coppin L, Jannin A, Odou MF, et al. Diseases associated with calcium-sensing receptor. Orphanet J Rare Dis. 2017 Jan;12(1):19.

138 Cheng SX, Lightfoot YL, Yang T, Zadeh M, Tang L, Sahay B, et al. Epithelial CaSR deficiency alters intestinal integrity and promotes proinflammatory immune responses. FEBS Lett. 2014 Nov;588(22):4158-66.

139 Sudo N, Chida Y, Aiba Y, Sonoda J, Oyama N, Yu XN, et al. Postnatal microbial colonization programs the hypothalamic-pituitary-adrenal system for stress response in mice. J Physiol. 2004 Jul;558(Pt 1):263-75.

140 Lach G, Schellekens H, Dinan TG, Cryan JF. Anxiety, depression, and the microbiome: a role for gut peptides. Neurotherapeutics. 2018 Jan;15(1):36-59.

141 Friedland RP, Chapman MR. The role of microbial amyloid in neurodegeneration. PLoS Pathog. 2017 Dec; 13(12):e1006654.

142 Zhou Y, Blanco LP, Smith DR, Chapman MR. Bacterial amyloids. Methods Mol Biol. 2012;849:303-20.

143 Epstein EA, Chapman MR. Polymerizing the fibre between bacteria and host cells: the biogenesis of functional amyloid fibres. Cell Microbiol. 2008 Jul;10(7):1413-20.

144 Friedland RP. Mechanisms of molecular mimicry involving the microbiota in neurodegeneration. J Alzheimers Dis. 2015;45(2):349-62.

145 Hsiao EY, McBride SW, Hsien S, Sharon G, Hyde ER, McCue T, et al. Microbiota modulate behavioral and physiological abnormalities associated with neurodevelopmental disorders. Cell. 2013 Dec;155(7):1451-63.

146 Vogt NM, Kerby RL, Dill-McFarland KA, Harding SJ, Merluzzi AP, Johnson SC, et al. Gut microbiome alterations in Alzheimer's disease. Sci Rep. 2017 Oct;7(1):13537.

147 Chen WW, Zhang X, Huang WJ. Role of neuroinflammation in neurodegenerative diseases (Review) [Review]. Mol Med Rep. 2016 Apr;13(4):3391-6.

148 Scheltens P, Blennow K, Breteler MM, de Strooper B, Frisoni GB, Salloway S, et al. Alzheimer's disease. Lancet. 2016 Jul;388(10043):505-17.

149 Salazar N, Valdés-Varela L, González S, Gueimonde M, de Los Reyes-Gavilán CG. Nutrition and the gut microbiome in the elderly. Gut Microbes. 2017 Mar;8(2):82-97.

150 Holzer P, Reichmann F, Farzi A. Neuropeptide Y, peptide YY and pancreatic polypeptide in the gut-brain axis. Neuropeptides. 2012 Dec;46(6):261-74. 
151 Erdő F, Denes L, de Lange E. Age-associated physiological and pathological changes at the blood-brain barrier: A review. J Cereb Blood Flow Metab. 2017 Jan;37(1):4-24.

152 Sawada N, Murata M, Kikuchi K, Osanai M, Tobioka H, Kojima T, et al. Tight junctions and human diseases. Med Electron Microsc. 2003 Sep;36(3):147-56.

153 Förster C. Tight junctions and the modulation of barrier function in disease. Histochem Cell Biol. 2008 Jul; 130(1):55-70.

154 Luettig J, Rosenthal R, Barmeyer C, Schulzke JD. Claudin-2 as a mediator of leaky gut barrier during intestinal inflammation. Tissue Barriers. 2015 Apr;3(1-2):e977176.

155 Zihni C, Mills C, Matter K, Balda MS. Tight junctions: from simple barriers to multifunctional molecular gates. Nat Rev Mol Cell Biol. 2016 Sep;17(9):564-80.

156 Awad WA, Hess C, Hess M. Enteric pathogens and their toxin-induced disruption of the intestinal barrier through alteration of tight junctions in chickens. Toxins (Basel). 2017 Feb;9(2):60.

157 Rossi M, Johnson DW, Campbell KL. The kidney-gut axis: implications for nutrition care. J Ren Nutr. 2015 Sep; 25(5):399-403.

158 Coppo R. The gut-kidney axis in IgA nephropathy: role of microbiota and diet on genetic predisposition. Pediatr Nephrol. 2018 Jan;33(1):53-61.

159 Wing MR, Patel SS, Ramezani A, Raj DS. Gut microbiome in chronic kidney disease. Exp Physiol. 2016 Apr; 101(4):471-7.

160 Fernandez-Prado R, Esteras R, Perez-Gomez MV, Gracia-Iguacel C, Gonzalez-Parra E, Sanz AB, et al. Nutrients turned into toxins: microbiota modulation of nutrient properties in chronic kidney disease. Nutrients. 2017 May; 9(5):E489.

161 De Preter V, Vanhoutte T, Huys G, Swings J, Rutgeerts P, Verbeke K. Effect of lactulose and Saccharomyces boulardii administration on the colonic urea-nitrogen metabolism and the bifidobacteria concentration in healthy human subjects. Aliment Pharmacol Ther. 2006 Apr;23(7):963-74.

162 Vince AJ, Burridge SM. Ammonia production by intestinal bacteria: the effects of lactose, lactulose and glucose. J Med Microbiol. 1980 May;13(2):177-91.

163 Lees HJ, Swann JR, Wilson ID, Nicholson JK, Holmes E. Hippurate: the natural history of a mammalian-microbial cometabolite. J Proteome Res. 2013 Apr;12(4):1527-46.

164 de Andrade LS, Ramos CI, Cuppari L. The cross-talk between the kidney and the gut: implications for chronic kidney disease. Nutrire. 2017;42(1):27.

$165 \mathrm{Mu}$ Q, Kirby J, Reilly CM, Luo XM. Leaky Gut As a Danger Signal for Autoimmune Diseases. Front Immunol. 2017 May; 8:598.

$166 \mathrm{Hu}$ X, Wang T, Jin F. Alzheimer's disease and gut microbiota. Sci China Life Sci. 2016 0ct;59(10):1006-23.

167 Braniste V, Al-Asmakh M, Kowal C, Anuar F, Abbaspour A, Tóth M, et al. The gut microbiota influences bloodbrain barrier permeability in mice. Sci Transl Med. 2014 Nov;6(263):263ra158.

168 Kelly JR, Kennedy PJ, Cryan JF, Dinan TG, Clarke G, Hyland NP. Breaking down the barriers: the gut microbiome, intestinal permeability and stress-related psychiatric disorders. Front Cell Neurosci. 2015 Oct; 9:392.

169 Capaldo CT, Powell DN, Kalman D. Layered defense: how mucus and tight junctions seal the intestinal barrier. J Mol Med (Berl). 2017 Sep;95(9):927-34.

170 Amasheh S, Fromm M, Günzel D. Claudins of intestine and nephron - a correlation of molecular tight junction structure and barrier function. Acta Physiol (Oxf). 2011 Jan;201(1):133-40.

171 Hoyles L, Snelling T, Umlai UK, Nicholson JK, Carding SR, Glen RC, et al. Microbiome-host systems interactions: protective effects of propionate upon the blood-brain barrier. Microbiome. 2018 Mar;6(1):55.

172 Fang X. Potential role of gut microbiota and tissue barriers in Parkinson's disease and amyotrophic lateral sclerosis. Int J Neurosci. 2016 Sep;126(9):771-6.

173 Ransohoff RM. How neuroinflammation contributes to neurodegeneration. Science. 2016 Aug;353(6301): 777-83.

174 Erickson MA, Banks WA. Blood-brain barrier dysfunction as a cause and consequence of Alzheimer's disease. J Cereb Blood Flow Metab. 2013 Oct;33(10):1500-13.

175 Sagare AP, Bell RD, Zlokovic BV. Neurovascular defects and faulty amyloid- $\beta$ vascular clearance in Alzheimer's disease. J Alzheimers Dis. 2013;33(s1 Suppl 1):S87-100.

176 Tomimoto H, Akiguchi I, Suenaga T, Nishimura M, Wakita H, Nakamura S, et al. Alterations of the blood-brain barrier and glial cells in white-matter lesions in cerebrovascular and Alzheimer's disease patients. Stroke. 1996 Nov; 27(11):2069-74.

177 Sabatino A, Regolisti G, Brusasco I, Cabassi A, Morabito S, Fiaccadori E. Alterations of intestinal barrier and microbiota in chronic kidney disease. Nephrol Dial Transplant. 2015 Jun;30(6):924-33.

178 Browne TC, McQuillan K, McManus RM, O’Reilly JA, Mills KH, Lynch MA. IFN- $\gamma$ Production by amyloid $\beta$-specific Th1 cells promotes microglial activation and increases plaque burden in a mouse model of Alzheimer's disease. J Immunol. 2013 Mar;190(5):2241-51.

179 Li X, Melief E, Postupna N, Montine KS, Keene CD, Montine TJ. Prostaglandin E2 receptor subtype 2 regulation of scavenger receptor CD36 modulates microglial A 342 phagocytosis. Am J Pathol. 2015 Jan;185(1):230-9.

180 Rangaraju S, Raza SA, Li NX, Betarbet R, Dammer EB, Duong D, et al. Differential Phagocytic Properties of CD45low Microglia and CD45high Brain Mononuclear Phagocytes-Activation and Age-Related Effects. Front Immunol. 2018 Mar; 9:405. 
181 Ray R, Juranek JK, Rai V. RAGE axis in neuroinflammation, neurodegeneration and its emerging role in the pathogenesis of amyotrophic lateral sclerosis. Neurosci Biobehav Rev. 2016 Mar;62:48-55.

182 Tóbon-Velasco JC, Cuevas E, Torres-Ramos MA. Receptor for AGEs (RAGE) as mediator of NF-kB pathway activation in neuroinflammation and oxidative stress. CNS Neurol Disord Drug Targets. 2014;13(9):1615-26.

183 Millington C, Sonego S, Karunaweera N, Rangel A, Aldrich-Wright JR, Campbell IL, et al. Chronic neuroinflammation in Alzheimer's disease: new perspectives on animal models and promising candidate drugs. Biomed Res Int. 2014;2014:309129.

184 Ghosh S, Wu MD, Shaftel SS, Kyrkanides S, LaFerla FM, Olschowka JA, et al. Sustained interleukin-1ß overexpression exacerbates tau pathology despite reduced amyloid burden in an Alzheimer's mouse model. J Neurosci. 2013 Mar;33(11):5053-64.

185 Hickman SE, Allison EK, El Khoury J. Microglial dysfunction and defective beta-amyloid clearance pathways in aging Alzheimer's disease mice. J Neurosci. 2008 Aug;28(33):8354-60.

186 Chio CC, Chang CH, Wang CC, Cheong CU, Chao CM, Cheng BC, et al. Etanercept attenuates traumatic brain injury in rats by reducing early microglial expression of tumor necrosis factor- $\alpha$. BMC Neurosci. 2013 Mar; 14(1):33.

187 Vernocchi P, Del Chierico F, Putignani L. Gut microbiota profiling: metabolomics based approach to unravel compounds affecting human health. Front Microbiol. 2016 Jul; 7:1144.

188 Lee ES, Song EJ, Nam YD. Dysbiosis of gut microbiome and its impact on epigenetic regulation. J Clin Epigenet. 2017;3:2.

189 Russo R, Cristiano C, Avagliano C, De Caro C, La Rana G, Raso GM, et al. Gut-brain axis: role of lipids in the regulation of inflammation, pain and CNS diseases. Curr Med Chem. 2017 Feb;24(999):1.

190 Flint HJ, Scott KP, Duncan SH, Louis P, Forano E. Microbial degradation of complex carbohydrates in the gut. Gut Microbes. 2012 Jul-Aug;3(4):289-306.

191 Vinke PC, El Aidy S, van Dijk G. The role of supplemental complex dietary carbohydrates and gut microbiota in promoting cardiometabolic and immunological health in obesity: lessons from healthy non-obese individuals. Front Nutr. 2017 Jul; 4:34.

192 Lin HV, Frassetto A, Kowalik EJ Jr, Nawrocki AR, Lu MM, Kosinski JR, et al. Butyrate and propionate protect against diet-induced obesity and regulate gut hormones via free fatty acid receptor 3-independent mechanisms. PLoS One. 2012;7(4):e35240.

193 Tahara Y, Yamazaki M, Sukigara H, Motohashi H, Sasaki H, Miyakawa H, et al. Gut microbiota-derived short chain fatty acids induce circadian clock entrainment in mouse peripheral tissue. Sci Rep. 2018 Jan;8(1):1395.

194 Oleskin AV, Shenderov BA. Neuromodulatory effects and targets of the SCFAs and gasotransmitters produced by the human symbiotic microbiota. Microb Ecol Health Dis. 2016 Jul;27:30971.

195 Li X, Shimizu Y, Kimura I. Gut microbial metabolite short-chain fatty acids and obesity. Biosci Microbiota Food Health. 2017;36(4):135-40.

196 den Besten G, van Eunen K, Groen AK, Venema K, Reijngoud DJ, Bakker BM. The role of short-chain fatty acids in the interplay between diet, gut microbiota, and host energy metabolism. J Lipid Res. 2013 Sep;54(9):232540.

197 Tan J, McKenzie C, Potamitis M, Thorburn AN, Mackay CR, Macia L. The role of short-chain fatty acids in health and disease. Adv Immunol. 2014;121:91-119.

198 Cole GM, Ma Q-L, Frautschy SA: Dietary fatty acids and the aging brain. Nutr Rev. 2010;68 Suppl 2:S102-11.

199 Ho L, Ono K, Tsuji M, Mazzola P, Singh R, Pasinetti GM. Protective roles of intestinal microbiota derived short chain fatty acids in Alzheimer's disease-type beta-amyloid neuropathological mechanisms. Expert Rev Neurother. 2018 Jan;18(1):83-90.

200 Wang D, Ho L, Faith J, Ono K, Janle EM, Lachcik PJ, et al. Role of intestinal microbiota in the generation of polyphenol-derived phenolic acid mediated attenuation of Alzheimer's disease $\beta$-amyloid oligomerization. Mol Nutr Food Res. 2015 Jun;59(6):1025-40.

201 Psichas A, Sleeth ML, Murphy KG, Brooks L, Bewick GA, Hanyaloglu AC, et al. The short chain fatty acid propionate stimulates GLP-1 and PYY secretion via free fatty acid receptor 2 in rodents. Int J Obes. 2015 Mar;39(3): 424-9.

202 Lewis KN, Mele J, Hayes JD, Buffenstein R. Nrf2, a guardian of healthspan and gatekeeper of species longevity. Integr Comp Biol. 2010 Nov;50(5):829-43.

203 Figarska SM, Vonk JM, Boezen HM. NFE2L2 polymorphisms, mortality, and metabolism in the general population. Physiol Genomics. 2014 Jun;46(12):411-7.

204 Akkasheh G, Kashani-Poor Z, Tajabadi-Ebrahimi M, Jafari P, Akbari H, Taghizadeh M, et al. Clinical and metabolic response to probiotic administration in patients with major depressive disorder: A randomized, doubleblind, placebo-controlled trial. Nutrition. 2016 Mar;32(3):315-20.

205 Akbari E, Asemi Z, Daneshvar Kakhaki R, Bahmani F, Kouchaki E, Tamtaji OR, et al. Effect of probiotic supplementation on cognitive function and metabolic status in Alzheimer's disease: a randomized, double-blind and controlled trial. Front Aging Neurosci. 2016 Nov;8:256.

206 Jamilian M, Bahmani F, Vahedpoor Z, Salmani A, Tajabadi-Ebrahimi M, Jafari P, et al. Effects of probiotic supplementation on metabolic status in pregnant women: a randomized, double-blind, placebo-controlled trial. Arch Iran Med. 2016 Oct;19(10):687-682.

207 Bambury A, Sandhu K, Cryan JF, Dinan TG. Finding the needle in the haystack: systematic identification of psychobiotics. Br J Pharmacol. 2017 Dec. DOI: https://doi.org/10.1111/bph.14127. 
Welcome: Intestinal Microbiota Dysfunction and Dementia

208 Daulatzai MA: Obesity and gut's dysbiosis promote neuroinflammation, cognitive impairment, and vulnerability to Alzheimer's disease: new directions and therapeutic implications. J Mol Genet Med 2014;S1:005. DOI: https://doi.org/10.4172/1747-0862.S1-005..

209 Zhao H, Shi Y, Luo X, Peng L, Yang Y, Zou L. The Effect of Fecal Microbiota Transplantation on a Child with Tourette Syndrome. Case Rep Med. 2017;2017:6165239.

210 Kang DW, Adams JB, Gregory AC, Borody T, Chittick L, Fasano A, et al. Microbiota Transfer Therapy alters gut ecosystem and improves gastrointestinal and autism symptoms: an open-label study. Microbiome. 2017 Jan; 5(1): 10 .

211 Ceccarelli G, Brenchley JM, Cavallari EN, Scheri GC, Fratino M, Pinacchio C, et al. Impact of high-dose multistrain probiotic supplementation on neurocognitive performance and central nervous system immune activation of HIV-1 infected individuals. Nutrients. 2017 Nov;9(11):1269.

212 Chunchai T, Thunapong W, Yasom S, Wanchai K, Eaimworawuthikul S, Metzler G, et al. Decreased microglial activation through gut-brain axis by prebiotics, probiotics, or synbiotics effectively restored cognitive function in obese-insulin resistant rats. J Neuroinflammation. 2018 Jan;15(1):11.

213 Savignac HM, Corona G, Mills H, Chen L, Spencer JP, Tzortzis G, et al. Prebiotic feeding elevates central brain derived neurotrophic factor, N-methyl-D-aspartate receptor subunits and D-serine. Neurochem Int. 2013 Dec; 63(8):756-64.

214 Maqsood R, Stone TW. The gut-brain axis, BDNF, NMDA and CNS disorders. Neurochem Res. 2016 Nov;41(11): 2819-35.

215 Williams S, Chen L, Savignac HM, Tzortzis G, Anthony DC, Burnet PW. Neonatal prebiotic (BGOS) supplementation increases the levels of synaptophysin, GluN2A-subunits and BDNF proteins in the adult rat hippocampus. Synapse. 2016 Mar;70(3):121-4.

216 Herpertz-Dahlmann B, Seitz J, Baines J. Food matters: how the microbiome and gut-brain interaction might impact the development and course of anorexia nervosa. Eur Child Adolesc Psychiatry. 2017 Sep;26(9):103141.

217 Li C, Cai YY, Yan ZX. Brain-derived neurotrophic factor preserves intestinal mucosal barrier function and alters gut microbiota in mice. Kaohsiung J Med Sci. 2018 Mar;34(3):134-41.

218 Westfall S, Lomis N, Kahouli I, Dia SY, Singh SP, Prakash S. Microbiome, probiotics and neurodegenerative diseases: deciphering the gut brain axis. Cell Mol Life Sci. 2017 Oct;74(20):3769-87.

219 Santocchi E, Guiducci L, Fulceri F, Billeci L, Buzzigoli E, Apicella F, et al. Gut to brain interaction in Autism Spectrum Disorders: a randomized controlled trial on the role of probiotics on clinical, biochemical and neurophysiological parameters. BMC Psychiatry. 2016 Jun;16(1):183.

220 Slavin J. Fiber and prebiotics: mechanisms and health benefits. Nutrients. 2013 Apr;5(4):1417-35.

221 Pandey KR, Naik SR, Vakil BV. Probiotics, prebiotics and synbiotics- a review. J Food Sci Technol. 2015 Dec; 52(12):7577-87.

222 Burokas A, Arboleya S, Moloney RD, Peterson VL, Murphy K, Clarke G, et al. Targeting the microbiota-gut-brain axis: prebiotics have anxiolytic and antidepressant-like effects and reverse the impact of chronic stress in mice. Biol Psychiatry. 2017 Oct;82(7):472-87.

223 Vaiserman AM, Koliada AK, Marotta F. Gut microbiota: A player in aging and a target for anti-aging intervention. Ageing Res Rev. 2017 May;35:36-45.

$224 \mathrm{Hu}$ X, Wang T, Jin F. Alzheimer's disease and gut microbiota. Sci China Life Sci. 2016 Oct;59(10):1006-23.

225 Cenit MC, Sanz Y, Codoñer-Franch P. Influence of gut microbiota on neuropsychiatric disorders. World J Gastroenterol. 2017 Aug;23(30):5486-98.

226 Britton E, McLaughlin JT. Ageing and the gut. Proc Nutr Soc. 2013 Feb;72(1):173-7.

227 Soenen S, Rayner CK, Jones KL, Horowitz M. The ageing gastrointestinal tract. Curr Opin Clin Nutr Metab Care. 2016 Jan;19(1):12-8.

228 Rayner CK, Horowitz M. Physiology of the ageing gut. Curr Opin Clin Nutr Metab Care. 2013 Jan;16(1):33-8.

229 Saraswati S, Sitaraman R. Aging and the human gut microbiota-from correlation to causality. Front Microbiol. 2015 Jan;5:764. 